\title{
Molecular Circuits of Resolution in the Eye
}

\author{
Elvira L. Liclican and Karsten Gronert* \\ Vision Science Program, School of Optometry, University of California, Berkeley \\ E-mail: kgronert@berkeley.edu
}

Received February 1, 2010; Revised April 28, 2010; Accepted April 29, 2010; Published June 1, 2010

Lipid autacoids have well-established key roles in physiology and pathophysiology. Eicosanoids derived from $\omega-6$ arachidonic acid (AA) have long been recognized for their roles in cardiovascular and renal functions, and vascular tone, as well as regulating inflammatory and immune functions. It is now appreciated that AA is a substrate for generating lipid mediators with anti-inflammatory and proresolving properties, namely lipoxins (i.e., LXA 4 ), which are an integral component for the successful execution of beneficial and essential acute inflammatory responses. In addition to AA, the $\omega-3$ polyunsaturated fatty acids (PUFAs) eicosapentaenoic acid (EPA) and docosahexaenoic acid (DHA) also serve as substrates to generate potent and protective autacoids, such as resolvins and neuroprotectin (i.e., NPD1), respectively. These $\omega$-3-derived signals may mediate the remarkable protective action of essential dietary $\omega-3$ PUFAs. Formation and bioactivity of lipid mediators in the eye are relatively unexplored and of considerable interest, as the eye contains highly specialized tissues, including the transparent avascular and immune-privileged cornea, and the neuro-retina. A rapidly emerging field has identified key biosynthetic enzymes, receptors, and temporally defined endogenous

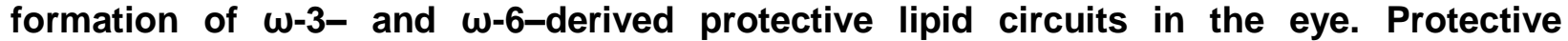
endogenous roles of $\mathrm{LXA}_{4}$ and NPD1 have been established utilizing lipidomic analysis, knockout mice, and pharmacological, genetic, and dietary manipulation, providing compelling evidence that these intrinsic lipid autacoid circuits play essential roles in restraining inflammation, promoting wound healing, inhibiting pathological angiogenesis, and providing neuroprotection in the delicate visual axis.

KEYWORDS: inflammatory resolution, $\omega-3$ polyunsaturated fatty acids, lipoxin $A_{4}$, resolvins, neuroprotectin D1, lipoxygenase

\section{INTRODUCTION}

The eye is one of the primary sense organs and is composed of a posterior outgrowth of the central nervous system, the retina, and an anterior highly modified transparent skin, the avascular cornea. The main function of this unique and specialized organ is to convert light energy into nerve action potentials, a highly conserved process that is dependent on maintaining the refractive properties of the cornea, lens, aqueous humor, and vitreous humor; the formation and reabsorption of fluids that keep intraocular pressure constant; and preserving the function of retinal neurons. In order to preserve function, it is essential for the delicate visual axis to maintain an avascular, transparent, and/or immune-privileged state in several ocular tissues. 
Hence, the threat of inflammation is incompatible with good vision, especially in the highly specialized anterior surface (i.e., cornea) and neural tissue (i.e., retina) of the eye. However, the visual axis faces constant inflammatory and immunogenic threats, as the ocular surface is continuously exposed to the shearing stress of eyelid motion, prolonged periods of hypoxia associated with sleep, and, due to its anatomical positioning, environmental pathogens and irritants. In addition, the retina is vulnerable to bloodborne pathogens, oxidative stress, inflammatory mediators, and systemic inflammatory/immune disease, despite its isolation by a well-developed blood tissue barrier. Thus, it is not surprising that the eye contains highly developed circuits to control inflammation, maintain host defense, and promote ordered and rapid wound healing, thereby protecting essential vision[1,2,3,4,5,6,7,8,9].

Although it shares many features with immunity in other tissues, the ocular immune response is atypical. Like other tissues that are extremely vulnerable to inflammation-induced tissue injury, such as the brain and pregnant uterus, the eye has developed key adaptations to minimize collateral tissue injury by restraining immune and inflammatory responses[2,3,4,9,10,11]. A remarkable feature of the eye is the presence of avascular, transparent, and immune-privileged sites, such as the cornea. In particular, the cornea actively maintains an anti-inflammatory and immunosuppressive microenvironment that can accept, sometimes indefinitely, allogeneic grafts without immune rejections and heals rapidly with almost no scarring in response to mild injury while maintaining unwavering host defense[3,4,5,6,9,12,13,14,15,16,17]. Execution of these fundamental and self-resolving processes in the eye is clearly regulated by interdependent circuits and temporally defined arrays of mediators, which remain to be clearly defined. Lipid mediators of inflammation, proliferation, tissue remodeling, and/or angiogenesis have wellappreciated and key roles in physiology and pathophysiology. Compared to long-standing research efforts that have defined lipid autacoid circuits as therapeutic targets, and delineated their complex and pleiotropic molecular mechanisms of action in most tissues/organs, our understanding of lipid mediator circuits in the eye is just beginning to unfold[6,16,18,19,20,21,22,23,24]. An emerging body of work provides strong evidence that protective lipid circuits are critical components of inflammatory resolution, apoptosis, wound healing, and pathological angiogenesis in the eye, which is the focus of this review.

\section{LIPID AUTACOID CIRCUITS IN THE EYE}

Eicosanoids are derived from the essential polyunsaturated fatty acid (PUFA) arachidonic acid (AA, $\omega-6$ $\mathrm{C} 20$ :4). Following injury, AA is released and can be metabolized in a cell-specific fashion by three families of enzymes, cyclooxygenases (COXs), lipoxygenases (LOXs), and cytochrome P450s (CYP450s), to form lipid autacoids. All three families of enzymes are functionally expressed in the eye as are G protein-coupled receptors for COX-derived prostaglandins (PGs), and LOX-derived lipoxins (LXs) and leukotrienes (LTs), which mediate the actions of these distinct classes of potent lipid autacoids[6,16,19,20,21,25,26].

\section{Cyclooxygenase (COX)}

Early studies have shown that PGs are released during ocular inflammation[27]. However, most studies have focused on the ability of PGs, specifically $\mathrm{PGF}_{2 \alpha}$, to reduce intraocular pressure[28,29,30]. Thus, the role of PGs in ocular inflammation remains to be fully explored, which is underscored by the fact that despite the therapeutic use of nonsteroidal anti-inflammatory drugs (NSAIDs) for more than 100 years for reducing inflammation and inflammatory hyperalgesia in most tissues, the first ophthalmic topical use of NSAIDs was not until 1986 for maintaining pupil dilation after cataract surgery[31]. Several studies have demonstrated that COX-2 expression and PG formation are up-regulated in models of ocular inflammation[19,32,33,34,35,36]. Moreover, a role for PGs in regulating inflammation in most tissues of the eye is strongly supported by studies that have employed NSAIDs, PG analogs, and PG receptor knockout mice[29,37,38,39,40]. COX-derived PGs exert diverse and sometimes opposing bioactivity, which is receptor- and cell type-specific, as well as temporally defined. In this regard, research efforts in 
the eye are only in the early stages. Specifically, $\mathrm{PGE}_{2}$, acting through four distinct receptors (EP1, EP2, EP3, and EP4) that are expressed in the eye[41], can induce vascular, pro-, or anti-inflammatory effects and biosynthetic pathways for proresolving lipid autacoids (i.e., LX), as well as regulate fibrosis[6,42,43,44,45,46,47,48]. However, the endogenous role of $\mathrm{PGE}_{2}$ in the eye remains to be elucidated. It is now appreciated that PGs also have important roles in the active resolution of inflammation[42,49,50]. In particular, $\mathrm{PGD}_{2}$ and its cyclopentenone PG breakdown product, 15-deoxy $\Delta$ $\mathrm{PGJ}_{2}$ (Fig. 1), control the balance of cytokines and chemokines that regulate leukocyte influx during acute inflammation, as well as macrophage efflux to draining lymph nodes, leading to resolution[49,51]. Further, 15-deoxy $\Delta-\mathrm{PGJ}_{2}$ can inhibit activation of NF- $\mathrm{kB}$ and up-regulate expression of the cytoprotective and anti-inflammatory heme-oxygenase-1[49,52,53]. $\mathrm{PGF}_{2 \alpha}$, which is the primary treatment option for lowering ocular hypertension[28], has also been reported to regulate inflammatory resolution in a carageenin-induced pleurisy model, along with $\mathrm{PGD}_{2}$ and 15 -deoxy $\Delta-\mathrm{PGJ}_{2}[54,55,56]$. However, the endogenous formation and bioactivity of these protective PG circuits have not been explored in the eye.
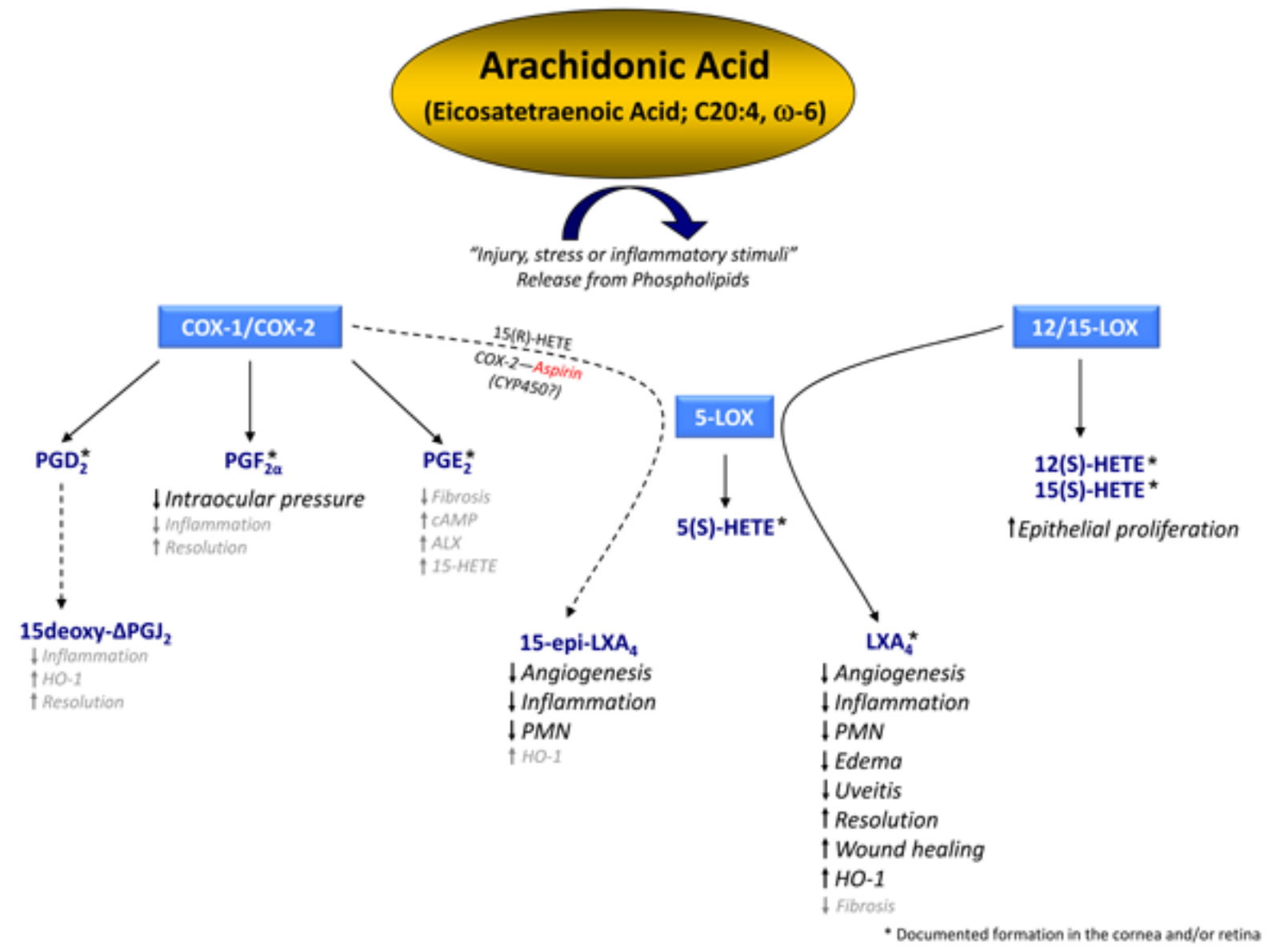

FIGURE 1. Protective AA ( $\omega-6)$-derived circuits in ocular inflammation. Following injury, stress, or inflammatory stimuli, AA ( $\omega-6)$ is released from phospholipid pools and can be metabolized by COX or LOX to form lipid autacoids with anti-inflammatory and proresolving properties. Black font denotes established bioactivity in the eye, gray font denotes potential bioactivity not yet explored in the eye.

\section{Lipoxygenase (LOX)}

Lipoxygenases (5-, 12-, and 15-LOX) initially produce fatty acid hydroxyperoxides by stereoselective insertion of molecular oxygen at specific carbons in PUFAs to form 5(S)-, 12(S)-, or 15(S)- 
hydroperoxides (H(p)ETE), respectively, if AA (eicosatetraenoic acid) is the substrate. These unstable hydroperoxides are rapidly hydrolyzed to form monohydroxy fatty acids (HETE), or can be converted to epoxides (5-LOX, 15-LOX) and/or further metabolized to pro- or anti-inflammatory lipid mediators, LT or LX, respectively, in the same cell or by cell-cell interactions. Several studies have demonstrated LOX activity in the retina[57,58,59,60], lens[61,62,63], and cornea[16,64,65,66,67] as evidenced by speciesspecific formation of 15-HETE, 12-HETE, or 5-HETE that was attenuated by general LOX inhibitors. There is considerable species-specific variation in the expression and function of 12-LOX and 15-LOX enzymes. However, enzymatic, gene, and protein data obtained from dog, mouse, rat, rabbit, and human tissues clearly indicate that 12/15-LOX (human, ALOX15; murine, Alox15) is a predominant enzyme in the retina and cornea. RT-PCR analysis and PCR cloning have demonstrated expression of 15-LOX type 1 and 2 (ALOX15 and ALOX15B) in human corneas, whose functional expression is strongly supported by the observation that human corneas and corneal epithelial cells produce one prominent HETE, namely, 15(S)-HETE[65,66,68,69,70]. Monkey corneal epithelial cells also predominantly express 15-LOX[71]. Elucidation of the LOX pathways in the mouse eye has been more complicated, owing to the expression of at least five distinct 12-LOX enzymes in mice. In addition to a 12/15-LOX (Alox15), mice express platelet-type (Alox12) and epidermal-type 12-LOX (Aloxe), which show prominent expression in epithelial cells[72,73,74,75]. mRNA expression of Alox15, Alox12, Aloxe, and 5-LOX (Alox5) has been detected in mouse corneas. However, Alox15 is the most abundant mRNA transcript[76] and evidence from Western blot analysis indicates that platelet-type 12-LOX protein is not expressed in the eye[73]. $12 / 15$-LOX is highly and selectively expressed in the corneal epithelium, as de-epithelialization of the mouse cornea completely abrogated its mRNA expression[76]. Functional expression of both 5-LOX and 12/15-LOX in the mouse cornea is evidenced by endogenous 5-HETE, 15 HETE, as well as LXA $_{4}$ formation[76], which is significantly impaired in 12/15-LOX-deficient mice[16]. Human retinal pigment epithelial cells express 15-LOX type 1, as its genetic knockdown results in a significant reduction in 15HETE and $\mathrm{LXA}_{4}$ formation[77], and 12/15-LOX is also expressed in the rat retina[60]. Immunohistochemistry of a whole mouse eye (Fig. 2) provides further evidence for the selective and high expression of 15-LOX, especially in epithelial cells of the cornea, retina, and lens. The endogenous role of the resident 15-LOX circuit in the eye is largely protective, as it is a key enzyme for the generation of the anti-inflammatory and proresolving eicosanoid $\mathrm{LXA}_{4}$.

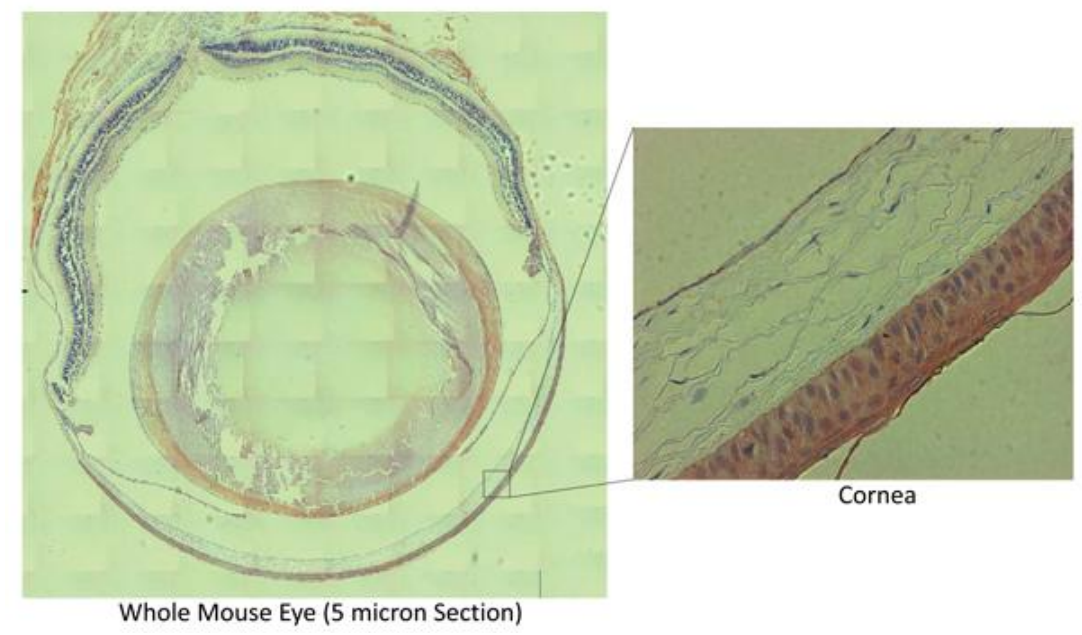

FIGURE 2. 12/15-LOX (Alox15) is highly and selectively expressed in epithelial cells of the cornea, retina, and lens. Representative image of a 5- $\mu \mathrm{m}$ section of a healthy, uninjured, whole eye obtained from Balb/c mice, probed with an anti-12/15-LOX antibody, and a magnified section of the cornea. 


\section{Cytochrome P450 (CYP450)}

Cytochrome P450 (CYP450) enzymes generate epoxide- and hydroxyeicosanoids, and are ubiquitously expressed throughout the body. They have long been recognized for their roles in xenobiotic metabolism, vascular tone, and cardiovascular and renal functions[78,79,80,81,82,83], but evidence now implicates an emerging role for CYP450 in inflammation[84,85,86,87]. This is of particular interest in the eye, as genetic linkage analysis and mutation studies have linked the CYP1B1 gene to the pathogenesis of glaucoma[88]. Further, CYP2C-derived epoxyeicosatrienoic acids have been implicated in hypoxiainduced retinal angiogenesis[89]. CYP450 has been identified in the corneal epithelium of several animal species, including humans, mice, and rabbits, and studies have established it as a primary corneal epithelial inflammatory pathway in experimental models of ocular surface inflammation[84]. In the cornea, CYP4B1 metabolizes AA to 12(R)-hydroxyeicosatetraenoic acid (12(R)-HETE), which is further metabolized to 12(R)-hydroxyeicosatrienoic acid (12(R)-HETrE). 12(R)-HETrE is a potent angiogenic factor and exerts inflammatory actions, including vasodilation and neutrophil chemotaxis[90]. However, it is important to note that CYP450 enzymes can also promote proresolving pathways in other tissues. Specifically, it has been shown that CYP450 enzymes in some epithelial cells can initiate the formation of a $\mathrm{LXA}_{4}$ isomer, namely 15-epi-LXA 4 , by generating 15(R)-HETE[91], which resists metabolic inactivation[92]. It remains to be determined if CYP450 enzymes contribute towards endogenous formation of $\mathrm{LXA}_{4}$ in the eye.

\section{Platelet-Activating Factor (PAF)}

Platelet-activating factor (PAF) is a prominent proinflammatory lipid autacoid that is synthesized by a variety of cell types, and exerts diverse physiological and pathological effects[18,19,36,93,94,95]. Its role in inflammatory responses has been extensively investigated in many tissues, and its bioactivity includes microvascular leakage, vasodilation, and activation of several types of inflammatory cells, such as neutrophils, eosinophils, and macrophages[18,19,36,93,94,95]. Its formation has been documented in several tissues of the eye, including the cornea, retina, iris, and ciliary body, and is a key mediator of corneal inflammatory responses[18,19,36]. In addition, PAF impairs re-epithelialization after corneal injury and promotes neovascularization. The effects of PAF are mediated through a G protein-coupled receptor, PAF-R, that activates signals involved in inflammation, wound healing, and apoptosis, and whose corneal expression is up-regulated following injury[18,19,36]. Indeed, the central role of PAF in corneal inflammatory responses is evident by studies that demonstrate that PAF-R antagonists reduce apoptosis, inflammatory cell infiltration, and expression of inflammatory cytokines, as well as prevent the development of keratitis and neovascularization[19,36,96,97].

\section{LIPID AUTACOID CIRCUITS OF RESOLUTION IN THE EYE}

A hallmark response to injury and infection is the recruitment of effector cells of host defense, such as polymorphonuclear leukocytes (PMNs), macrophages, and lymphocytes[8]. However, execution of the vital, highly frequent, and reoccurring inflammatory response necessitates active resolution in order to restore normal tissue function; this is especially critical for the delicate visual axis, as uncontrolled inflammation and disordered wound repair can impair visual acuity and lead to blindness. In this regard, a rapidly evolving field of research has identified distinct classes of endogenous anti-inflammatory and proresolving lipid mediators. An impressive body of work has demonstrated that these endogenous lipid circuits are integral components of an acute inflammatory response, which is dependent on the balanced activation of pro- and anti-inflammatory circuits, controlled wound healing, and active resolution of leukocytes[42,50,98,99,100,101]. Further, emerging evidence places these protective lipid circuits as key components of the ocular inflammatory/reparative response. 


\section{5-LOX and $\mathrm{LXA}_{4}$ Circuit}

Lipoxins (LXs) were the first endogenous lipid mediators with anti-inflammatory and proresolving properties to be discovered[102]. LXs are lipoxygenase-interaction products that are formed from AA during PMN interactions with platelets, endothelial cells, or epithelial cells, and are formed predominantly during the resolution phase of acute inflammation[103,104,105,106]. 12/15-LOX is a key enzyme for their biosynthesis (Fig. 1) and, thus, it is not surprising that the enzyme is highly expressed in epithelial cells and is one of the most prominent inducible genes in human monocytes[107]. An impressive body of work has established that $\mathrm{LXA}_{4}$ is an important mediator of inflammatory resolution. Indeed, several lines of evidence from numerous animal models of acute inflammation, asthma, pathological angiogenesis, host defense, and innate immune responses, as well as human clinical data, indicate that $\mathrm{LXA}_{4}$ and the $\mathrm{LXA}_{4}$ receptor (ALX) constitute an essential protective eicosanoid circuit[103,104,105,106,108].

The bioactivity of $\mathrm{LXA}_{4}$ is mediated via its G protein-coupled receptor, ALX[109]. Importantly, data from receptor transgenic mice and detailed structure-activity studies have established specific ALX receptors in humans (FPRL1) and mice (Fprl1 and Fpr-rs2) as a molecular mechanism for LXA 's protective in vivo actions[109]. LXA $_{4}$ has cell-specific actions with leukocytes, lymphocytes, and epithelial and endothelial cells, all of which cumulate in reducing the inflammatory response, regulating PMN function, clearing of apoptotic PMNs, and promoting wound healing[50,105,109,110,111,112, $113,114]$.

In recent years, the essential role of this anti-inflammatory circuit in maintaining an orchestrated and beneficial ocular inflammatory/reparative response has been investigated. A study in 1998 documented the expression of ALX mRNA in human corneas, providing the first evidence for a potential specific bioactivity of $\mathrm{LXA}_{4}$ in the eye[115]. Subsequent studies in mice revealed that $\mathrm{LXA}_{4}$ is produced in the healthy, uninjured mouse cornea[16,76,116]. The fact that the avascular and immune-privileged cornea highly expresses 15-LOX and ALX points toward a central role of this protective lipid circuit in the healthy cornea. In the healthy cornea that contains no leukocytes, 12/15-LOX and ALX are predominantly expressed in epithelial cells, as $\mathrm{LXA}_{4}$ formation and expression of 12/15-LOX and ALX are abrogated by de-epithelialization and restored during epithelial wound healing[16,76]. Hence, in the cornea, $\mathrm{LXA}_{4}$ formation, unlike in most tissues, is not directly dependent on infiltrating leukocytes from the cornea[76].

Direct evidence for a protective role of endogenous $\mathrm{LXA}_{4}$ in the cornea has been obtained through studies in mice deficient in key $\mathrm{LXA}_{4}$ biosynthetic enzymes, namely, 12/15-LOX and 5LOX[6,16,76,116]. Mice with a targeted deletion of 12/15-LOX display delayed epithelial wound healing, which correlates with impaired endogenous corneal $\mathrm{LXA}_{4}$ formation[76]. Pharmacological amplification of this circuit by topical treatment with $\mathrm{LXA}_{4}$ increased the rate of wound healing, reduced tissue damage following thermal cauterization, and rescued delayed wound healing in 12/15-LOX knockout mice. The protective effects of $\mathrm{LXA}_{4}$ following de-epithelialization were not associated with inhibiting PMN infiltration[76], which is distinct from LXA ${ }_{4}$ 's established mechanism of action to inhibit PMN recruitment in several in vivo models of acute inflammation[105]. Hence, in the context of a mild and self-resolving epithelial injury, recruitment of PMNs to the injured cornea is a beneficial protective response that likely depends on a resident $\mathrm{LXA}_{4}$ circuit to restrain activation of these primary and precarious effector cells. Indeed, although early studies indicate that PMNs have no significant or a negative impact on wound healing[117], several studies in the eye now demonstrate that inhibition of PMN infiltration into the cornea is associated with impaired epithelial wound healing[118,119,120,121,122]. Topical treatment with $\mathrm{LXA}_{4}$ also markedly reduced the formation of KC (mouse homolog to human IL-8) and monocyte chemoattractant protein-1[16,76], chemokines that are prominent in acute inflammatory lesions of the eye and keratitis[123,124,125]. Thus, in addition to accelerating epithelial wound healing, $\mathrm{LXA}_{4}$ inhibits the formation of selective epithelial inflammatory markers in the cornea. 
As in most tissues, the eye expresses heme-oxygenases (HO-1 and HO-2), which constitute an essential cytoprotective system that metabolizes heme and generates antioxidants and the bioactive gas carbon monoxide. HO-1 has emerged as a highly inducible and essential cytoprotective gene whose amplification by genetic or pharmacological approaches causes remarkable antiproliferative, antiinflammatory, and antiapoptotic actions[126,127,128,129,130]. Thus, it is striking that acute and selfresolving corneal injury dramatically up-regulates the resident $\mathrm{HO}$ system. The essential role of the HO system in the cornea was established by employing HO-2 knockout mice that failed to induce HO-1 expression in the injured cornea[116,131,132]. In these HO-deficient mice, normal self-resolving inflammation and complete wound closure was shifted to chronic inflammation, failed wound healing, and pronounced corneal neovascularization. Strikingly, the phenotype of chronic injury and inflammatory neovascularization correlated with a $50 \%$ reduction in endogenous $\mathrm{LXA}_{4}$ formation. Subsequent studies in mice with an impaired $\mathrm{LXA}_{4}$ biosynthetic pathway (12/15-LOX knockout) demonstrated that induction of HO-1 was impaired and correlated with amplified PMN infiltration, chemokine formation, and delayed wound healing[116]. More importantly, add back experiments with topical LXA $_{4}$ to the 12/15-LOX knockout mice restored normal HO-1 expression, wound healing, and inflammation. Experiments with human corneal epithelial cells confirmed that specific 15-LOX-derived mediators, $\mathrm{LXA}_{4}, \mathrm{NPD} 1$, and 17HDHA, amplify expression of cytoprotective HO-1, a bioactivity which was not shared by 15HETE[116]. These studies suggest an interdependence of two intrinsic protective circuits in the cornea[116,131], namely $\mathrm{HO}$ and the $\mathrm{LXA}_{4}$ circuit. In this regard, it is important to point out that 15deoxy $\Delta-\mathrm{PGJ}_{2}$ and stable analogs of $\mathrm{LXA}_{4}$ have been shown to up-regulate $\mathrm{HO}-1$ expression in macrophages and endothelial cells, respectively[52,53,133].

A protective role for $\mathrm{LXA}_{4}$ has also been identified in intraocular inflammatory diseases, specifically endotoxin-induced uveitis (EIU)[134]. EIU is a common animal model that exhibits many of the key features of human uveitis, including dilation of vessels, macromolecule leakage, edema, and infiltration of leukocytes and lymphocytes. Topical treatment with $\mathrm{LXA}_{4}$ greatly attenuated EIU[134]. The preventative and therapeutic effect of $\mathrm{LXA}_{4}$ on EIU correlated with reduced protein leakage and PMN infiltration into the aqueous humor of the eye, as well as a reduction in proinflammatory mediator (i.e., TNF- $\alpha, \mathrm{COX}-2$, and vascular endothelial growth factor; VEGF) production and NF- $\kappa \mathrm{B}$ activation.

A recent report defined the endogenous role of the $\mathrm{LXA}_{4}$ circuit and a $\mathrm{LXA}_{4}$ stable analog in chronic injury-induced inflammatory neovascularization[135,136]. In a model of chronic inflammation (i.e., suture-induced injury), topical treatment with $\mathrm{LXA}_{4}$, but not its metabolic precursor 15-HETE, attenuated formation of blood vessels and reduced expression of critical mediators of inflammatory neovascularization, including key members of the VEGF family (i.e., VEGF-A and the VEGF receptor-3, FLT4)[135]. Treatment with a $\mathrm{LXA}_{4}$ stable analog also reduced the expression of the proinflammatory cytokines TNF- $\alpha$, IL-1 $\alpha$, and IL-1 $\beta[136]$. More importantly, pathological angiogenesis correlated with selective up-regulation of 12/15-LOX activity and expression, and regulated expression of $\mathrm{LXA}_{4}$ receptors, which likely is a protective tissue response to counter-regulate nonresolving inflammation. This notion is supported by genetic deletion of 12/15-LOX and 5-LOX, key and obligatory enzymes in the formation of $\mathrm{LXA}_{4}$, respectively[16,100,109], which led to pronounced exacerbation of inflammatory neovascularization coincident with increased expression of VEGF-A and FLT4[135]. Topical treatment with $\mathrm{LXA}_{4}$ rescued 15-LOX knockout mice from exacerbated angiogenesis, providing direct evidence for the $\mathrm{LXA}_{4}$ circuit as an endogenous regulator of pathological angiogenesis in the cornea.

Taken together, well-established and distinct experimental models of inflammation, namely acute, self-resolving inflammation and chronic inflammation with neovascularization, have demonstrated that the endogenous $\mathrm{LXA}_{4}$ circuit has an essential role in limiting the sequelae of injury in the delicate visual axis and interacts with other cytoprotective systems to amplify protective circuits, which may endow ocular tissues such as the cornea with privileged injury responses.

Aside from $\mathrm{LXA}_{4}$, other LOX-derived AA metabolites, namely, 12(S)-HETE and 15(S)-HETE, can exert beneficial actions in the cornea. 12(S)-HETE and 15(S)-HETE can function as intracellular second messengers for growth factors and modulate the proliferation of corneal epithelial cells, thereby promoting wound closure[19,36]. In addition, topically applied 15(S)-HETE increased mucin secretion 
and protected the cornea from dessicating-induced damage in animal models of dry eye[36]. Although the mechanism of action has not been clearly defined, it has been shown to involve translocation and activation of protein kinase $\mathrm{C}-\alpha$, which is necessary for goblet cell proliferation, thereby increasing mucin secretion[36]. However, the endogenous role of 15(S)-HETE depends on "a where and a when", as topical application of 15(S)-HETE promotes angiogenesis in the cornea[135] and in human corneal epithelial cells, reduces basal expression of the cytoprotective and anti-inflammatory HO-1[116].

\section{w-3 PUFA-Derived Circuits}

In addition to AA, cells release other essential PUFAs, including eicosapentaenoic acid (EPA, $\omega-3$ C20:5) and docosahexaenoic acid (DHA, $\omega-3$ C22:6), in response to stress, injury, or inflammatory stimuli (Fig. $3)$. The importance of essential PUFAs is underscored by the well-established roles of $\omega$-3 PUFAs in normal growth and development, and maintaining human health[137,138,139,140,141,142,143,144]. Moreover, epidemiological studies and clinical trials have demonstrated that consumption of fish oils, which are enriched in EPA and DHA, is cardio- and renoprotective, and lowers the incidence of inflammatory and autoimmune diseases[137,138,142,145,146,147,148,149,150,151,152]. In particular, DHA has been shown to exert anti-inflammatory and immunosuppressive effects[150,153].
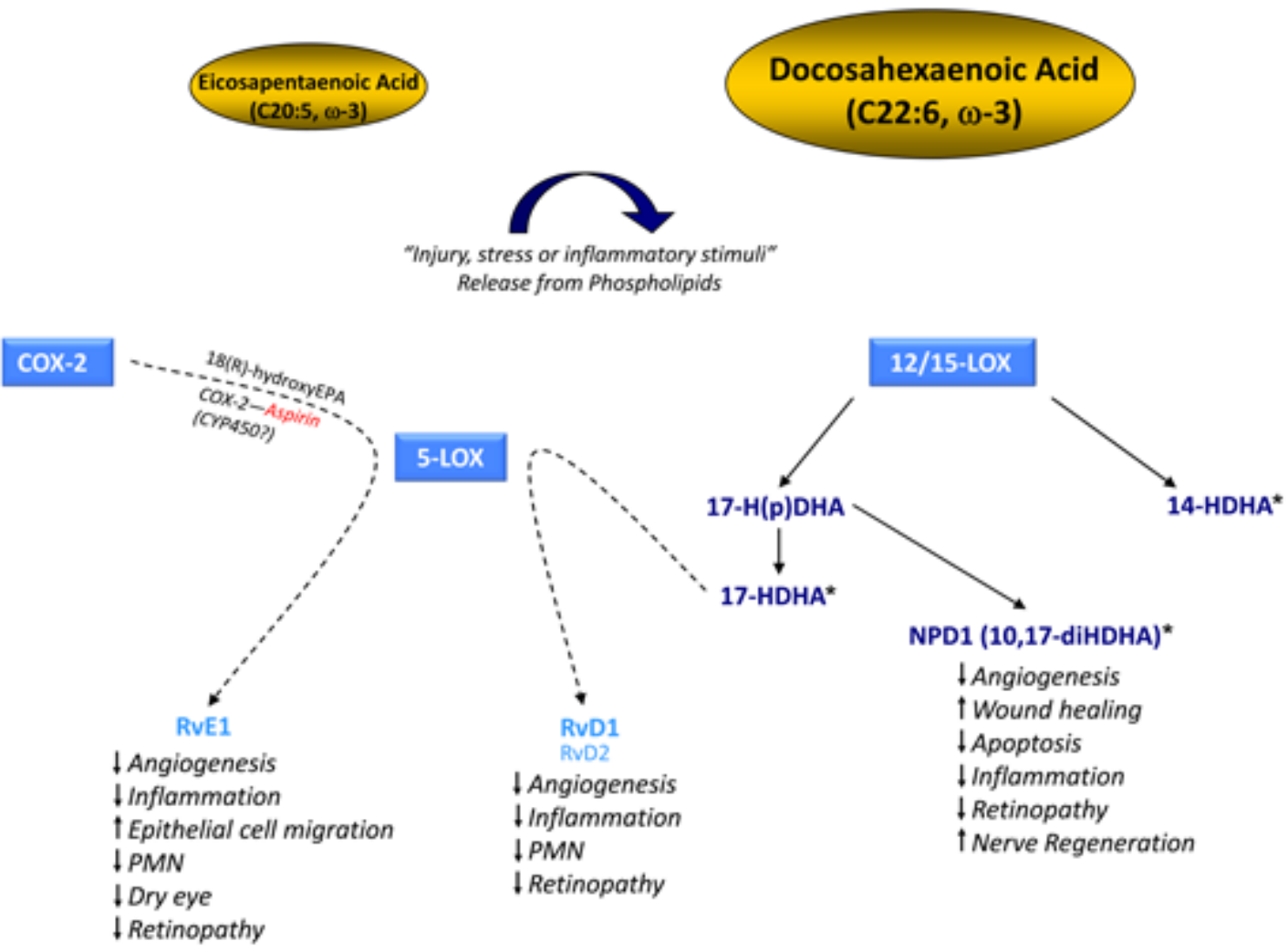

- Documented formation in the cornes and/or retina

FIGURE 3. Protective $\omega-3$ PUFA-derived circuits in ocular inflammation. Following injury, stress, or inflammatory stimuli, $\omega-3$ essential fatty acids, including EPA and DHA, can be released from phospholipid pools to generate LOX-derived resolvins (Rv) and neuroprotectin D1 (NPD1), respectively. These novel EPA- and DHA-derived lipid autacoids exert specific protective actions that control inflammation and pathological angiogenesis, promote epithelial wound healing, and ultimately maintain ocular health. Dark blue font denotes DHA-derived products, light blue font denotes EPA-derived products. 
The protective and beneficial effects of dietary $\omega-3$ PUFAs are now recognized as an important factor for ocular health, a notion that is strongly supported by both experimental and clinical data[154,155,156,157,158,159]. In a murine model of macular degeneration, a diet enriched in DHA and EPA reduced the development of retinal lesions[160], and in a murine model of oxygen-induced retinopathy, increasing $\omega-3$ tissue levels by dietary or genetic manipulation reduced pathological retinal neovascularization[161]. Moreover, several studies have shown that infant formulas supplemented with DHA led to an enhancement in visual resolution acuity, maturation of retinal function, and overall neurological performance in preterm and term infants[20,162,163]. Importantly, the therapeutic potential and clinical relevance of supplementing $\omega-3$ intake is exemplified by current clinical trials (i.e., AgeRelated Eye Disease Study) that have demonstrated that dietary $\omega-3$ PUFA intake is inversely associated with neovascular age-related macular degeneration (AMD)[164]. Consumption of fish oil-enriched diets containing $\omega-3$ DHA and EPA by persons with moderate-to-high risk for AMD not only lowered the risk of developing neovascular AMD, but also reduced the progression from bilateral drusen to central geographic atrophy over a 12-year period[165,166]. Increased dietary intake of $\omega-3$ PUFAs was also associated with a decreased incidence of dry eye syndrome in a large, well-characterized population of women participating in the Women's Health Study[167]. In parallel, treatment with $\alpha$-linolenic acid, a precursor for EPA and DHA, reversed the signs and underlying inflammatory changes seen in a murine model of dry eye; leukocyte infiltration into the cornea was reduced, as was corneal and conjunctival expression of TNF- $\alpha$ and IL-1 $\alpha[168]$.

The discovery of novel EPA- and DHA-derived lipid autacoids has provided a major breakthrough in understanding the potential molecular mechanism through which these essential $\omega$-3 PUFAs mediate their remarkable beneficial actions[100,101,110,169,170]. These PUFAs can be metabolized, in a manner analogous to LX formation (Figs. 1 and 3), to generate a novel class of immune regulatory and antiinflammatory protective lipids termed resolvins ( Rv), so named because they were first identified as resolution-phase interaction products. Based on the substrate, they belong to the RvE series if derived from EPA or the RvD series if derived from DHA[100,101,171,172]. In addition to resolvins, endogenous formation of another DHA-derived lipid mediator, 10,17(S)-docosatriene, has been identified in both humans and rodents[169,173]. 10(R),17(S)-docosatriene has been termed neuroprotectin D1 (NPD1) if generated in neural tissue and based on its protective actions in neurons, glial cells, stroke, and animal models of Alzheimer's disease; the term protectin D1 (PD1) has been used if the bioactivity and endogenous formation are outside the nervous system[20,100,101,154,171,174,175]. NPD1 is of particular interest since its biosynthetic pathway, unlike that of resolvins and LXs, is triggered by a single LOX enzyme (Fig. 3), namely, 15-LOX, which is highly expressed in epithelial cells of both the cornea and retina. Data from 12/15-LOX knockout mice and siRNA targeting human 15-LOX have identified ALOX15 as a key enzyme for the formation of NPD1. The complete structure of NPD1, RvD1, RvE1, and RvD2 have recently been disclosed[176,177,178,179]. These EPA- and DHA-derived lipid autacoids exhibit anti-inflammatory and proresolving bioactivity, which are stereoselective and evoked in the picoto nanomolar range. The protective $\omega$-3-derived signals have distinct, but overlapping, bioactivity and both in vitro and in vivo experiments have demonstrated that similar to $\mathrm{LXA}_{4}$, resolvins and protectins reduce leukocyte infiltration, regulate cytokines/chemokines and reactive oxygen species, and increase macrophage ingestion of apoptotic PMNs[20,98,146,169,171].

It is important to recognize that without marked dietary supplementation, EPA concentrations in human tissues, plasma, and milk are very low. By contrast, DHA, like AA, is found in all human tissues, plasma, and milk at concentrations 1-20\% of total fatty acids[180]. Moreover, in the cerebral cortex, sperm, and retina, DHA is present at higher concentrations than AA[180]. In particular, retinal photoreceptor outer segments have the highest DHA content of any cell $[181,182,183]$ and unusual DHAretention ability[184,185,186]. Prolonged dietary deprivation of $\omega-3$ PUFAs has been shown to correlate with severe visual impairment[187,188]. The tissue levels of DHA exceed those of EPA five- to 30 fold in most tissues and more than 100-fold in the retina and central nervous system, which is consistent with the fact that human metabolic pathways for all dietary $\omega-3$ PUFAs ( $\alpha$-linolenic acid [C18:3] or EPA) preferentially lead to the formation of DHA. However, endogenous formation of DHA from $\omega-3$ PUFA 
precursors, such as $\alpha$-linolenic acid, is very inefficient. It is now recognized that the major source of DHA is direct consumption, which truly places DHA as an essential fatty acid. Hence, it is not surprising that several lines of evidence illustrate a critical role for DHA in human physiology, namely, neuronal and retinal photoreceptor functions[20,174,186,189]. Indeed, experimental evidence demonstrates decreased blood levels of DHA in various forms of retinitis pigmentosa and in animal models of inherited retinal degeneration[20].

Like the cornea, the subretinal space is an immune-privileged site and the retinal pigmented epithelial cells (RPE) have an important role in maintaining the immune privilege[190]. RPE are highly specialized, and are essential to maintain and phagocytose the photoreceptors (rods and cones), recycle DHA back to the inner segments during photoreceptor outer segment renewal, and form the retinal-blood barrier. Failure of RPE cells to function properly leads to photoreceptor damage or death, and, consequently, impaired vision and eventual blindness. The photoreceptors and RPE compose a region of the retina that is particularly prone to oxidative stress. As increased oxidative stress, trauma, or retinal detachment induces RPE dysfunctions that can contribute to neovascularization and subsequently AMD or other retinal degenerations, RPE have developed endogenous mechanisms to counteract these challenges[20,154,174,175,191]. In this regard, DHA, which is enriched in these cells, exerts a striking protective effect. When confronted with excessive oxidative stress, RPE cells increase production of DHA-derived NPD1[192]. NPD1 inhibits oxidative stress-mediated proinflammatory gene induction and apoptosis, and, consequently, promotes RPE cell survival[193]. Further, human RPE cells deficient in 15LOX type 1 exhibit increased sensitivity to oxidative stress-induced apoptosis, which was rescued selectively by NPD1, but not other 15-LOX type 1-derived metabolites (i.e., 12(S)-HETE, 15(S)HETE)[77]. NPD1 has also been shown to inhibit retinal ganglion cell apoptosis following optic nerve transaction[60], as well as inhibit pathological retinal angiogenesis along with RvD1 and RvE1, an effect mediated in part through suppression of the inflammatory cytokine TNF- $\alpha$ [161]. In a recent report, RvD1 and RvE1 were also shown to reduce inflammatory signaling and PMN migration in choroid-retinal endothelial cells in vitro[194].

Recent reports also provide evidence for a role of $\omega$-3-derived lipid autacoids in the resolution of immune responses in the cornea. Importantly, endogenous formation of NPD1 and 17(S)-HDHA was first documented in both healthy and injured corneas obtained from mice fed an $\omega$-3-enriched diet[76]. Similar to the protective bioactivity of $\mathrm{LXA}_{4}$ following de-epithelialization, topical treatment with NPD1 accelerated wound healing without impairing PMN recruitment[76]. In a scratch wound assay, RvE1 and resolvin analogs were shown to stimulate human corneal epithelial cell migration via activation of phosphoinositide 3-kinase and p38 mitogen activated protein kinase signaling, thereby accelerating wound healing[195,196]. Resolvin analogs also exert beneficial effects in dry eye; in a mouse model of dry eye, topical application of RvE1 analogs increased tear production as well as epithelial cell density, suggesting that resolvins could play a role in maintaining the integrity of epithelia damaged by dry eye[197]. Expression of COX-2 and $\alpha$-smooth muscle actin was also decreased, as was macrophage infiltration. Hence, it is likely that the protective actions of $\omega$-3-derived lipid autacoids in dry eye are multifactorial, and involve modulation of the inflammatory and immune components. Indeed, RVE1 has been shown to inhibit PMN infiltration, regulate T-helper cell survival and differentiation, and regulate macrophage function and cytokine expression in animal models of acute and allergic inflammation[100,198,199]. In addition, RvD1 and RvE1 exert antiangiogenic effects in models of corneal neovascularization induced by suture or micropellets containing IL-1 $\beta$ or VEGF-A, which was associated with reducing leukocyte infiltration and the gene expression of inflammatory cytokines[136].

Maintenance of a healthy corneal surface is in part dependent on the integrity of corneal sensory nerves. Indeed, the impairment of corneal nerves disrupts the corneal reflex arc, affecting lacrimal gland function and subsequently tear production, causing dry eye[200]. Interestingly, recent studies now implicate a role for NPD1 in the regeneration of corneal nerves damaged after surgery[201,202]. Following photorefractive keratectomy, administration of DHA with nerve growth factor significantly increased nerve density and, more importantly, increased epithelial cell proliferation, demonstrating a healthy epithelium[202]. In subsequent studies, treatment with DHA and pigment epithelial-derived 
growth factor following lamellar keratectomy also promoted corneal nerve regeneration, which was associated with synthesis of NPD1[201]. Taken together, these studies demonstrate a role for DHAderived autacoids, namely, NPD1, in regenerating corneal innervation after refractive surgery, thereby repairing and protecting the ocular surface, and preventing the development of dry eye and neurotrophic keratopathies[200].

\section{CONCLUSION}

Inflammation is an essential and beneficial response to tissue insult, injury, hypoxia, and infection. A tightly regulated inflammatory program, and its successful execution and resolution, are particularly critical and highly evolved in the delicate visual axis, as uncontrolled ocular inflammation and disordered wound repair can lead to blindness. It is now appreciated that acute inflammation is a precarious innate response whose successful outcome is dependent on the balanced formation of pro- and antiinflammatory lipid autacoids, the active resolution of leukocytes, and restoration of homeostasis. In contrast to most tissues/organs, our understanding of lipid mediator circuits in the eye is relatively unexplored. A rapidly evolving body of work provides strong evidence for protective lipid circuits as key components of the ocular inflammatory/reparative response. Specifically, 15-LOX-derived autacoids, such as the eicosanoid $\mathrm{LXA}_{4}$ and DHA-derived NPD1, have emerged as central components of an intrinsic and essential protective pathway in the retina and cornea. The regulation and mechanisms of action for these intrinsic and protective lipid circuits remain to be clearly defined, and are of great clinical interest for the delicate visual axis as therapeutic targets and as a potential underlying cause of ocular diseases.

\section{ACKNOWLEDGMENTS}

We gratefully acknowledge grants from the National Institutes of Health, EY016136 and P30EY003176, for supporting research in the author's laboratory (K.G.), which is cited in this review.

\section{REFERENCES}

1. Kaplan, H.J. (2007) Anatomy and function of the eye. Chem. Immunol. Allergy 92, 4-10.

2. $\quad$ Streilein, J.W. (1995) Unraveling immune privilege. Science 270, 1158-1159.

3. Streilein, J.W. (2003a) Ocular immune privilege: the eye takes a dim but practical view of immunity and inflammation. J. Leukoc. Biol. 74, 179-185.

4. Streilein, J.W. (2003b) Ocular immune privilege: therapeutic opportunities from an experiment of nature. Nat. Rev. Immunol. 3, 879-889.

5. McDermott, A.M., Perez, V., Huang, A.J., Pflugfelder, S.C., Stern, M.E., Baudouin, C., Beuerman, R.W., Burns, A.R., Calder, V.L., Calonge, M., Chodosh, J., Coster, D.J., Dana, R., Hazlett, L.D., Jones, D.B., Kim, S.K., Knop, E., Li, D.Q., Mitchell, B.M., Niederkorn, J.Y., Pearlman, E., Wilhelmus, K.R., and Kurie, E. (2005) Pathways of corneal and ocular surface inflammation: a perspective from the cullen symposium. Ocul. Surf. 3, S131-138.

6. Gronert, K. (2008) Lipid autacoids in inflammation and injury responses: a matter of privilege. Mol. Interv. 8, $28-35$.

7. Niederkorn, J.Y. (2006) See no evil, hear no evil, do no evil: the lessons of immune privilege. Nat. Immunol. 7, 354359.

8. Kumar, V., Fausto, N., and Abbas, A. (2004) Robbins and Cotran Pathological Basis of Disease. W.B. Saunders, Philadelphia.

9. Ono, S.J. (2003) Immunity in the eye: lessons in organ-specific responses. J. Leukoc. Biol. 74, 149-150.

10. Kaplan, H.J. and Niederkorn, J.Y. (2007) Regional immunity and immune privilege. Chem. Immunol. Allergy 92, 1126.

11. Niederkorn, J.Y. and Kaplan, H.J. (2007) Rationale for immune response and the eye. Chem. Immunol. Allergy 92, 13 .

12. Hamrah, P., Huq, S.O., Liu, Y., Zhang, Q., and Dana, M.R. (2003) Corneal immunity is mediated by heterogeneous population of antigen-presenting cells. J. Leukoc. Biol. 74, 172-178. 
13. Niederkorn, J.Y. (2003) The immune privilege of corneal grafts. J. Leukoc. Biol. 74, 167-171.

14. Leopold, I.H. and Gaster, R.N. (1988) Ocular Inflammation and Anti-Inflammatory Drugs. Churchill Livingston, New York.

15. Waring, G.O., 3rd and Rodrigues, M.M. (1987) Patterns of pathologic response in the cornea. Surv. Ophthalmol. 31, 262-266.

16. Gronert, K. (2005) Lipoxins in the eye and their role in wound healing. Prostaglandins Leukot. Essent. Fatty Acids 73, 221-229.

17. Cursiefen, C. (2007) Immune privilege and angiogenic privilege of the cornea. Chem. Immunol. Allergy 92, $50-57$.

18. Bazan, H. and Ottino, P. (2002) The role of platelet-activating factor in the corneal response to injury. Prog. Retin. Eye Res. 21, 449-464.

19. Bazan, H.E. (2005) Cellular and molecular events in corneal wound healing: significance of lipid signalling. Exp. Eye Res. 80, 453-463.

20. Bazan, N.G. (2006) Cell survival matters: docosahexaenoic acid signaling, neuroprotection and photoreceptors. Trends Neurosci. 29, 263-271.

21. Laniado-Schwartzman, M. and Dunn, M.W. (2003) Cytochrome P450-derived eicosanoids mediators of ocular surface inflammation. Adv. Exp. Med. Biol. 525, 47-54.

Bazan, H.E. (1987) Corneal injury alters eicosanoid formation in the rabbit anterior segment in vivo. Invest. Ophthalmol. Vis. Sci. 28, 314-319.

23. Bazan, H.E., Birkle, D.L., Beuerman, R.W., and Bazan, N.G. (1985) Inflammation-induced stimulation of the synthesis of prostaglandins and lipoxygenase-reaction products in rabbit cornea. Curr. Eye Res. 4, 175-179. Tjebbes, G.W., van Delft, J.L., and van Haeringen, N.J. (1993) Production of lipid mediators in experimental keratitis of rabbit eye. J. Lipid Mediat. 8, 87-93. Talahalli, R., Zarini, S., Sheibani, N., Murphy, R.C., and Gubitosi-Klug, R.A. (2009) Elevated glucose increases synthesis of leukotrienes in the mouse model of diabetic retinopathy. Invest. Ophthalmol. Vis. Sci.

26. Kulkarni, P.S. and Srinivasan, B.D. (1989) Cyclooxygenase and lipoxygenase pathways in anterior uvea and conjunctiva. Prog. Clin. Biol. Res. 312, 39-52.

27. Eakins, K.E., Whitelocke, R.A., Perkins, E.S., Bennett, A., and Unger, W.G. (1972) Release of prostaglandins in ocular inflammation in the rabbit. Nat. New Biol. 239, 248-249.

28. Bito, L.Z. (2001) A new approach to the medical management of glaucoma, from the bench to the clinic, and beyond: the Proctor Lecture. Invest. Ophthalmol. Vis. Sci. 42, 1126-1133.

29. Srinivasan, B.D. and Kulkarni, P.S. (1989) Inhibitors of Arachidonic Acid Cascades in the Management of Ocular Inflammation. Alan R. Liss, New York.

30. Camras, C.B., Bito, L.Z., and Eakins, K.E. (1977) Reduction of intraocular pressure by prostaglandins applied topically to the eyes of conscious rabbits. Invest. Ophthalmol. Vis. Sci. 16, 1125-1134.

31. Bartlett, J.D. and Jaanus, S.D. (2008) Clinical Ocular Pharmacology. Butterworth-Heinemann, St. Louis.

32. Bito, L.Z. (1986) Prostaglandins and other eicosanoids: their ocular transport, pharmacokinetics, and therapeutic effects. Trans. Ophthalmol. Soc. U. K. 105(Pt 2), 162-170.

33. Bazan, H.E. (1989) The Synthesis and Effects of Eicosanoids in Avascular Ocular Tissues. Alan R. Liss, New York.

34. Bazan, N.G. and Allan, G. (1997) Signal transduction and gene expression in the eye: a contemporary view of the pro-inflammatory, anti-inflammatory and modulatory roles of prostaglandins and other bioactive lipids. Surv. Ophthalmol. 41(Suppl 2), S23-34.

35. Hurst, J.S. and Bazan, H.E. (1995) Activation of the phospholipase/cyclooxygenase cascade in the rabbit cornea by platelet-activating factor is challenged by PAF receptor antagonists. J. Ocul. Pharmacol. Ther. 11, 329-337.

36. Kenchgowda, S. and Bazan, H.E. (2010) Significance of lipid mediators in corneal injury and repair. J. Lipid Res. 51, 879-891.

37. Biswas, S., Bhattacherjee, P., Paterson, C.A., Maruyama, T., and Narumiya, S. (2007) Modulation of ocular inflammatory responses by EP1 receptors in mice. Exp. Eye Res. 84, 39-43.

38. Biswas, S., Bhattacherjee, P., Paterson, C.A., Tilley, S.L., and Koller, B.H. (2006) Ocular inflammatory responses in the EP2 and EP4 receptor knockout mice. Ocul. Immunol. Inflamm. 14, 157-163.

39. Baranano, D.E., Kim, S.J., Edelhauser, H.F., Durairaj, C., Kompella, U.B., and Handa, J.T. (2009) Efficacy and pharmacokinetics of intravitreal non-steroidal anti-inflammatory drugs for intraocular inflammation. $B r . J$. Ophthalmol. 93, 1387-1390.

40. Ueda, M., Sugatani, J., Unezaki, S., Ito, Y., Miki, H., Uyama, M., and Ito, S. (1997) Involvement of prostaglandin E2 in rabbit corneal injury by anterior segment ischaemia. Prostaglandins Leukot. Essent. Fatty Acids 57, $285-291$.

41. Biswas, S., Bhattacherjee, P., and Paterson, C.A. (2004) Prostaglandin E2 receptor subtypes, EP1, EP2, EP3 and EP4 in human and mouse ocular tissues--a comparative immunohistochemical study. Prostaglandins Leukot. Essent. Fatty Acids 71, 277-288.

42. Serhan, C.N., Brain, S.D., Buckley, C.D., Gilroy, D.W., Haslett, C., O'Neill, L.A., Perretti, M., Rossi, A.G., and Wallace, J.L. (2007) Resolution of inflammation: state of the art, definitions and terms. FASEB J. 21, 325-332.

43. Tilley, S.L., Coffman, T.M., and Koller, B.H. (2001) Mixed messages: modulation of inflammation and immune responses by prostaglandins and thromboxanes. J. Clin. Invest. 108, 15-23. 
44. Huang, S.K., White, E.S., Wettlaufer, S.H., Grifka, H., Hogaboam, C.M., Thannickal, V.J., Horowitz, J.C., and Peters-Golden, M. (2009) Prostaglandin E(2) induces fibroblast apoptosis by modulating multiple survival pathways. FASEB J. 23, 4317-4326.

45. Sandulache, V.C., Parekh, A., Li-Korotky, H.S., Dohar, J.E., and Hebda, P.A. (2006) Prostaglandin E2 differentially modulates human fetal and adult dermal fibroblast migration and contraction: implication for wound healing. Wound Repair Regen. 14, 633-643.

46. Wang, D. and Dubois, R.N. (2006) Prostaglandins and cancer. Gut 55, 115-122.

47. Samuelsson, B., Morgenstern, R., and Jakobsson, P.J. (2007) Membrane prostaglandin E synthase-1: a novel therapeutic target. Pharmacol. Rev. 59, 207-224.

48. Harris, S.G., Padilla, J., Koumas, L., Ray, D., and Phipps, R.P. (2002) Prostaglandins as modulators of immunity. Trends Immunol. 23, 144-150.

49. Rajakariar, R., Yaqoob, M.M., and Gilroy, D.W. (2006) COX-2 in inflammation and resolution. Mol. Interv. 6, 199207.

50. Gilroy, D.W., Lawrence, T., Perretti, M., and Rossi, A.G. (2004) Inflammatory resolution: new opportunities for drug discovery. Nat. Rev. Drug Discov. 3, 401-416.

51. Rajakariar, R., Hilliard, M., Lawrence, T., Trivedi, S., Colville-Nash, P., Bellingan, G., Fitzgerald, D., Yaqoob, M.M., and Gilroy, D.W. (2007) Hematopoietic prostaglandin D2 synthase controls the onset and resolution of acute inflammation through PGD2 and 15-deoxyDelta12 14 PGJ2. Proc. Natl. Acad. Sci. U. S. A. 104, 20979-20984.

52. Zhuang, H., Pin, S., Li, X., and Dore, S. (2003) Regulation of heme oxygenase expression by cyclopentenone prostaglandins. Exp. Biol. Med. (Maywood) 228, 499-505.

53. Lee, T.S., Tsai, H.L., and Chau, L.Y. (2003) Induction of heme oxygenase-1 expression in murine macrophages is essential for the anti-inflammatory effect of low dose 15-deoxy-Delta 12,14-prostaglandin J2. J. Biol. Chem. 278, 19325-19330.

54. Gilroy, D.W., Colville-Nash, P.R., Willis, D., Chivers, J., Paul-Clark, M.J., and Willoughby, D.A. (1999) Inducible cycloxygenase may have anti-inflammatory properties. Nat. Med. 5, 698-701.

55. Colville-Nash, P.R., Gilroy, D.W., Willis, D., Paul-Clark, M.J., Moore, A.R., and Willoughby, D.A. (2005) Prostaglandin F2alpha produced by inducible cyclooxygenase may contribute to the resolution of inflammation. Inflammopharmacology 12, 473-476; discussion 477-480.

56. Gilroy, D.W., Colville-Nash, P.R., McMaster, S., Sawatzky, D.A., Willoughby, D.A., and Lawrence, T. (2003) Inducible cyclooxygenase-derived 15-deoxy(Delta)12-14PGJ2 brings about acute inflammatory resolution in rat pleurisy by inducing neutrophil and macrophage apoptosis. FASEB J. 17, 2269-2271.

57. Bazan, N.G. (1989a) Metabolism of arachidonic acid in the retina and retinal pigment epithelium: biological effects of oxygenated metabolites of arachidonic acid. Prog. Clin. Biol. Res. 312, 15-37.

58. Bazan, N.G. (1989b) The metabolism of omega-3 polyunsaturated fatty acids in the eye: the possible role of docosahexaenoic acid and docosanoids in retinal physiology and ocular pathology. Prog. Clin. Biol. Res. 312, 95112.

59. Augustin, A.J., Grus, F.H., Koch, F., and Spitznas, M. (1997) Detection of eicosanoids in epiretinal membranes of patients suffering from proliferative vitreoretinal diseases. Br. J. Ophthalmol. 81, 58-60.

60. Qin, Q., Patil, K.A., Gronert, K., and Sharma, S.C. (2008) Neuroprotectin D1 inhibits retinal ganglion cell death following axotomy. Prostaglandins Leukot. Essent. Fatty Acids 79, 201-207.

61. Haque, M.S., Arora, J.K., Dikdan, G., Lysz, T.W., and Zelenka, P.S. (1999) The rabbit lens epithelial cell line N/N1003A requires 12-lipoxygenase activity for DNA synthesis in response to EGF. Mol. Vis. 5, 8.

62. Arora, J.K., Lysz, T.W., and Zelenka, P.S. (1996) A role for 12(S)-HETE in the response of human lens epithelial cells to epidermal growth factor and insulin. Invest. Ophthalmol. Vis. Sci. 37, 1411-1418.

63. van Leyen, K., Duvoisin, R.M., Engelhardt, H., and Wiedmann, M. (1998) A function for lipoxygenase in programmed organelle degradation. Nature 395, 392-395.

64. Hurst, J.S., Balazy, M., Bazan, H.E., and Bazan, N.G. (1991) The epithelium, endothelium, and stroma of the rabbit cornea generate (12S)-hydroxyeicosatetraenoic acid as the main lipoxygenase metabolite in response to injury. J. Biol. Chem. 266, 6726-6730.

65. Chang, M.S., Schneider, C., Roberts, R.L., Shappell, S.B., Haselton, F.R., Boeglin, W.E., and Brash, A.R. (2005) Detection and subcellular localization of two 15S-lipoxygenases in human cornea. Invest. Ophthalmol. Vis. Sci. 46, 849-856.

66. Liminga, M., Hornsten, L., Sprecher, H.W., and Oliw, E.H. (1994) Arachidonate 15-lipoxygenase in human corneal epithelium and 12- and 15-lipoxygenases in bovine corneal epithelium: comparison with other bovine 12lipoxygenases. Biochim. Biophys. Acta 1210, 288-296.

67. Yamada, M. and Proia, A.D. (2000) 8(S)-hydroxyeicosatetraenoic acid is the lipoxygenase metabolite of arachidonic acid that regulates epithelial cell migration in the rat cornea. Cornea 19, S13-20.

68. Brash, A.R., Boeglin, W.E., and Chang, M.S. (1997) Discovery of a second 15S-lipoxygenase in humans. Proc. Natl. Acad. Sci. U. S. A. 94, 6148-6152.

69. Liminga, M., Von Malmborg, A., and Oliw, E. (1994) Lipoxygenases in human, monkey, and bovine corneal epithelia. Ann. N. Y. Acad. Sci. 744, 317-319. 
70. Liminga, M. and Oliw, E. (1999) cDNA cloning of 15-lipoxygenase type 2 and 12-lipoxygenases of bovine corneal epithelium. Biochim. Biophys. Acta 1437, 124-135.

71. Liminga, M., Fagerholm, P., and Oliw, E.H. (1994) Lipoxygenases in corneal epithelia of man and cynomolgus monkey. Exp. Eye Res. 59, 313-321.

72. Funk, C.D., Keeney, D.S., Oliw, E.H., Boeglin, W.E., and Brash, A.R. (1996) Functional expression and cellular localization of a mouse epidermal lipoxygenase. J. Biol. Chem. 271, 23338-23344.

73. Chen, X.S., Kurre, U., Jenkins, N.A., Copeland, N.G., and Funk, C.D. (1994) cDNA cloning, expression, mutagenesis of C-terminal isoleucine, genomic structure, and chromosomal localizations of murine 12-lipoxygenases. J. Biol. Chem. 269, 13979-13987.

74. Funk, C.D., Chen, X.S., Johnson, E.N., and Zhao, L. (2002) Lipoxygenase genes and their targeted disruption. Prostaglandins Other Lipid Mediat. 68-69, 303-312.

75. McDonnell, M., Davis, W., Jr., Li, H., and Funk, C.D. (2001) Characterization of the murine epidermal 12/15lipoxygenase. Prostaglandins Other Lipid Mediat. 63, 93-107.

76. Gronert, K., Maheshwari, N., Khan, N., Hassan, I.R., Dunn, M., and Laniado Schwartzman, M. (2005) A role for the mouse 12/15-lipoxygenase pathway in promoting epithelial wound healing and host defense. J. Biol. Chem. 280, $15267-15278$.

77. Calandria, J.M., Marcheselli, V.L., Mukherjee, P.K., Uddin, J., Winkler, J.W., Petasis, N.A., and Bazan, N.G. (2009) Selective survival rescue in 15-lipoxygenase-1-deficient retinal pigment epithelial cells by the novel docosahexaenoic acid-derived mediator, neuroprotectin D1. J. Biol. Chem. 284, 17877-17882.

78. Roman, R.J. (2002) P-450 metabolites of arachidonic acid in the control of cardiovascular function. Physiol. Rev. 82, 131-185.

79. Maier, K.G. and Roman, R.J. (2001) Cytochrome P450 metabolites of arachidonic acid in the control of renal function. Curr. Opin. Nephrol. Hypertens. 10, 81-87.

80. Zhou, S.F., Liu, J.P., and Chowbay, B. (2009) Polymorphism of human cytochrome P450 enzymes and its clinical impact. Drug Metab. Rev. 41, 89-295.

81. Roman, R.J., Maier, K.G., Sun, C.W., Harder, D.R., and Alonso-Galicia, M. (2000) Renal and cardiovascular actions of 20-hydroxyeicosatetraenoic acid and epoxyeicosatrienoic acids. Clin. Exp. Pharmacol. Physiol. 27, 855-865.

82. McGiff, J.C. and Quilley, J. (2001) 20-Hydroxyeicosatetraenoic acid and epoxyeicosatrienoic acids and blood pressure. Curr. Opin. Nephrol. Hypertens. 10, 231-237.

83. Fleming, I. (2001) Cytochrome p450 and vascular homeostasis. Circ. Res. 89, 753-762.

84. Schwartzman, M.L. (1997) Cytochrome P450 and Arachidonic Acid Metabolism in the Corneal Epithelium: Role in Inflammation. Plenum Press, New York.

85. Fleming, I. (2008) Vascular cytochrome p450 enzymes: physiology and pathophysiology. Trends Cardiovasc. Med. 18, 20-25.

86. Gauthier, K.M., Yang, W., Gross, G.J., and Campbell, W.B. (2007) Roles of epoxyeicosatrienoic acids in vascular regulation and cardiac preconditioning. J. Cardiovasc. Pharmacol. 50, 601-608.

87. Campbell, W.B. (2000) New role for epoxyeicosatrienoic acids as anti-inflammatory mediators. Trends Pharmacol. Sci. 21, 125-127.

88. Vasiliou, V. and Gonzalez, F.J. (2008) Role of CYP1B1 in glaucoma. Annu. Rev. Pharmacol. Toxicol. 48, $333-358$.

89. Michaelis, U.R., Xia, N., Barbosa-Sicard, E., Falck, J.R., and Fleming, I. (2008) Role of cytochrome P450 2C epoxygenases in hypoxia-induced cell migration and angiogenesis in retinal endothelial cells. Invest. Ophthalmol. Vis. Sci. 49, 1242-1247.

90. Seta, F., Patil, K., Bellner, L., Mezentsev, A., Kemp, R., Dunn, M.W., and Schwartzman, M.L. (2007) Inhibition of VEGF expression and corneal neovascularization by siRNA targeting cytochrome P450 4B1. Prostaglandins Other Lipid Mediat. 84, 116-127.

91. Claria, J., Lee, M.H., and Serhan, C.N. (1996) Aspirin-triggered lipoxins (15-epi-LX) are generated by the human lung adenocarcinoma cell line (A549)-neutrophil interactions and are potent inhibitors of cell proliferation. Mol. Med. 2, 583-596.

92. Serhan, C.N. and Chiang, N. (2002) Lipid-derived mediators in endogenous anti-inflammation and resolution: lipoxins and aspirin-triggered 15-epi-lipoxins. TheScientificWorldJOURNAL 2, 169-204.

93. Stafforini, D.M., McIntyre, T.M., Zimmerman, G.A., and Prescott, S.M. (2003) Platelet-activating factor, a pleiotrophic mediator of physiological and pathological processes. Crit. Rev. Clin. Lab. Sci. 40, 643-672.

94. Hanahan, D.J. (1986) Platelet activating factor: a biologically active phosphoglyceride. Annu. Rev. Biochem. 55, 483509.

95. Snyder, F. (1990) Platelet-activating factor and related acetylated lipids as potent biologically active cellular mediators. Am. J. Physiol. 259, C697-708.

96. Esquenazi, S., He, J., Bazan, H.E., and Bazan, N.G. (2004) Prevention of experimental diffuse lamellar keratitis using a novel platelet-activating factor receptor antagonist. J. Cataract Refract. Surg. 30, 884-891.

97. Esquenazi, S., He, J., Li, N., Bazan, N.G., Esquenazi, I., and Bazan, H.E. (2009) A novel platelet activating factor receptor antagonist reduces cell infiltration and expression of inflammatory mediators in mice exposed to desiccating conditions after PRK. Clin. Dev. Immunol. 2009, 138513. 
98. Schwab, J.M., Chiang, N., Arita, M., and Serhan, C.N. (2007) Resolvin E1 and protectin D1 activate inflammationresolution programmes. Nature 447, 869-874.

99. Serhan, C.N. and Savill, J. (2005) Resolution of inflammation: the beginning programs the end. Nat. Immunol. 6, 1191-1197.

100. Serhan, C.N., Chiang, N., and Van Dyke, T.E. (2008) Resolving inflammation: dual anti-inflammatory and proresolution lipid mediators. Nat. Rev. Immunol. 8, 349-361.

101. Serhan, C.N. and Chiang, N. (2008) Endogenous pro-resolving and anti-inflammatory lipid mediators: a new pharmacologic genus. Br. J. Pharmacol. 153(Suppl 1), S200-215.

102. Serhan, C.N., Hamberg, M., and Samuelsson, B. (1984) Trihydroxytetraenes: a novel series of compounds formed from arachidonic acid in human leukocytes. Biochem. Biophys. Res. Commun. 118, 943-949.

103. Serhan, C.N. (2002) Lipoxins and aspirin-triggered 15-epi-lipoxin biosynthesis: an update and role in antiinflammation and pro-resolution. Prostaglandins Other Lipid Mediat. 68-69, 433-455.

104. Lawrence, T., Willoughby, D.A., and Gilroy, D.W. (2002) Anti-inflammatory lipid mediators and insights into the resolution of inflammation. Nat. Rev. Immunol. 2, 787-795.

105. McMahon, B., Mitchell, S., Brady, H.R., and Godson, C. (2001) Lipoxins: revelations on resolution. Trends Pharmacol. Sci. 22, 391-395.

106. Maderna, P. and Godson, C. (2009) Lipoxins: resolutionary road. Br. J. Pharmacol. 158, 947-959.

107. Kuhn, H. and O'Donnell, V.B. (2006) Inflammation and immune regulation by 12/15-lipoxygenases. Prog. Lipid Res. 45, 334-356.

108. McMahon, B. and Godson, C. (2004) Lipoxins: endogenous regulators of inflammation. Am. J. Physiol. Renal Physiol. 286, F189-201.

109. Chiang, N., Serhan, C.N., Dahlen, S.E., Drazen, J.M., Hay, D.W., Rovati, G.E., Shimizu, T., Yokomizo, T., and Brink, C. (2006) The lipoxin receptor ALX: potent ligand-specific and stereoselective actions in vivo. Pharmacol. Rev. 58, 463-487.

110. Serhan, C.N. (2007) Resolution phase of inflammation: novel endogenous anti-inflammatory and proresolving lipid mediators and pathways. Annu. Rev. Immunol. 25, 101-137.

111. Jozsef, L., Zouki, C., Petasis, N.A., Serhan, C.N., and Filep, J.G. (2002) Lipoxin A4 and aspirin-triggered 15-epilipoxin A4 inhibit peroxynitrite formation, NF-kappa B and AP-1 activation, and IL-8 gene expression in human leukocytes. Proc. Natl. Acad. Sci. U. S. A. 99, 13266-13271.

112. Parkinson, J.F. (2006) Lipoxin and synthetic lipoxin analogs: an overview of anti-inflammatory functions and new concepts in immunomodulation. Inflamm. Allergy Drug Targets 5, 91-106.

113. Ariel, A., Chiang, N., Arita, M., Petasis, N.A., and Serhan, C.N. (2003) Aspirin-triggered lipoxin A4 and B4 analogs block extracellular signal-regulated kinase-dependent TNF-alpha secretion from human T cells. J. Immunol. 170, 6266-6272.

114. Aliberti, J., Hieny, S., Reis e Sousa, C., Serhan, C.N., and Sher, A. (2002) Lipoxin-mediated inhibition of IL-12 production by DCs: a mechanism for regulation of microbial immunity. Nat. Immunol. 3, 76-82.

115. Gronert, K., Gewirtz, A., Madara, J.L., and Serhan, C.N. (1998) Identification of a human enterocyte lipoxin A4 receptor that is regulated by interleukin (IL)-13 and interferon gamma and inhibits tumor necrosis factor alphainduced IL-8 release. J. Exp. Med. 187, 1285-1294.

116. Biteman, B., Hassan, I.R., Walker, E., Leedom, A.J., Dunn, M., Seta, F., Laniado-Schwartzman, M., and Gronert, K. (2007) Interdependence of lipoxin A4 and heme-oxygenase in counter-regulating inflammation during corneal wound healing. FASEB J. 21, 2257-2266.

117. Simpson, D.M. and Ross, R. (1972) The neutrophilic leukocyte in wound repair a study with antineutrophil serum. $J$. Clin. Invest. 51, 2009-2023.

118. Gan, L., Fagerholm, P., and Kim, H.J. (1999) Effect of leukocytes on corneal cellular proliferation and wound healing. Invest. Ophthalmol. Vis. Sci. 40, 575-581.

119. Vij, N., Roberts, L., Joyce, S., and Chakravarti, S. (2005) Lumican regulates corneal inflammatory responses by modulating Fas-Fas ligand signaling. Invest. Ophthalmol. Vis. Sci. 46, 88-95.

120. Li, Z., Burns, A.R., and Smith, C.W. (2006) Two waves of neutrophil emigration in response to corneal epithelial abrasion: distinct adhesion molecule requirements. Invest. Ophthalmol. Vis. Sci. 47, 1947-1955.

121. Li, Z., Rumbaut, R.E., Burns, A.R., and Smith, C.W. (2006) Platelet response to corneal abrasion is necessary for acute inflammation and efficient re-epithelialization. Invest. Ophthalmol. Vis. Sci. 47, 4794-4802.

122. Petrescu, M.S., Larry, C.L., Bowden, R.A., Williams, G.W., Gagen, D., Li, Z., Smith, C.W., and Burns, A.R. (2007) Neutrophil interactions with keratocytes during corneal epithelial wound healing: a role for CD18 integrins. Invest. Ophthalmol. Vis. Sci. 48, 5023-5029.

123. Cubitt, C.L., Tang, Q., Monteiro, C.A., Lausch, R.N., and Oakes, J.E. (1993) IL-8 gene expression in cultures of human corneal epithelial cells and keratocytes. Invest. Ophthalmol. Vis. Sci. 34, 3199-3206.

124. Rosenbaum, J.T., Planck, S.T., Huang, X.N., Rich, L., and Ansel, J.C. (1995) Detection of mRNA for the cytokines, interleukin-1 alpha and interleukin-8, in corneas from patients with pseudophakic bullous keratopathy. Invest. Ophthalmol. Vis. Sci. 36, 2151-2155. 
125. Spandau, U.H., Toksoy, A., Verhaart, S., Gillitzer, R., and Kruse, F.E. (2003) High expression of chemokines Groalpha (CXCL-1), IL-8 (CXCL-8), and MCP-1 (CCL-2) in inflamed human corneas in vivo. Arch. Ophthalmol. 121, $825-831$.

126. Otterbein, L.E., Soares, M.P., Yamashita, K., and Bach, F.H. (2003) Heme oxygenase-1: unleashing the protective properties of heme. Trends Immunol. 24, 449-455.

127. Hanselmann, C., Mauch, C., and Werner, S. (2001) Haem oxygenase-1: a novel player in cutaneous wound repair and psoriasis? Biochem. J. 353, 459-466.

128. Hegazi, R.A., Rao, K.N., Mayle, A., Sepulveda, A.R., Otterbein, L.E., and Plevy, S.E. (2005) Carbon monoxide ameliorates chronic murine colitis through a heme oxygenase 1-dependent pathway. J. Exp. Med. 202, 1703-1713.

129. Ryter, S.W., Alam, J., and Choi, A.M. (2006) Heme oxygenase-1/carbon monoxide: from basic science to therapeutic applications. Physiol. Rev. 86, 583-650.

130. Song, R., Kubo, M., Morse, D., Zhou, Z., Zhang, X., Dauber, J.H., Fabisiak, J., Alber, S.M., Watkins, S.C., Zuckerbraun, B.S., Otterbein, L.E., Ning, W., Oury, T.D., Lee, P.J., McCurry, K.R., and Choi, A.M. (2003) Carbon monoxide induces cytoprotection in rat orthotopic lung transplantation via anti-inflammatory and anti-apoptotic effects. Am. J. Pathol. 163, 231-242.

131. Seta, F., Bellner, L., Rezzani, R., Regan, R.F., Dunn, M.W., Abraham, N.G., Gronert, K., and Laniado-Schwartzman, M. (2006) Heme oxygenase-2 is a critical determinant for execution of an acute inflammatory and reparative response. Am. J. Pathol. 169, 1612-1623.

132. Bellner, L., Vitto, M., Patil, K.A., Dunn, M.W., Regan, R., and Laniado-Schwartzman, M. (2008) Exacerbated corneal inflammation and neovascularization in the HO-2 null mice is ameliorated by biliverdin. Exp. Eye Res. 87, 268-278.

133. Nascimento-Silva, V., Arruda, M.A., Barja-Fidalgo, C., Villela, C.G., and Fierro, I.M. (2005) Novel lipid mediator aspirin-triggered lipoxin A4 induces heme oxygenase-1 in endothelial cells. Am. J. Physiol. Cell Physiol. 289, C557563.

134. Medeiros, R., Rodrigues, G.B., Figueiredo, C.P., Rodrigues, E.B., Grumman, A., Jr., Menezes-de-Lima, O., Jr., Passos, G.F., and Calixto, J.B. (2008) Molecular mechanisms of topical anti-inflammatory effects of lipoxin A(4) in endotoxin-induced uveitis. Mol. Pharmacol. 74, 154-161.

135. Leedom, A.J., Sullivan, A.B., Dong, B., Lau, D., and Gronert, K. (2010) Endogenous LXA4 circuits are determinants of pathological angiogenesis in response to chronic injury. Am. J. Pathol. 176, 74-84.

136. Jin, Y., Arita, M., Zhang, Q., Saban, D.R., Chauhan, S.K., Chiang, N., Serhan, C.N., and Dana, R. (2009) Antiangiogenesis effect of the novel anti-inflammatory and pro-resolving lipid mediators. Invest. Ophthalmol. Vis. Sci. 50, 4743-4752.

137. De Caterina, R., Endres, S., Kristensen, S.D., and Schmidt, E.B., Eds. (1993) n-3 Fatty Acids and Vascular Disease. Springer-Verlag, London.

138. Simopoulos, A.P., Leaf, A., and Salem, N., Jr. (1999) Workshop on the essentiality of and recommended dietary intakes for omega-6 and omega-3 fatty acids. J. Am. Coll. Nutr. 18, 487-489.

139. Simopoulos, A.P. (1991) Omega-3 fatty acids in health and disease and in growth and development. Am. J. Clin. Nutr. 54, 438-463.

140. Simopoulos, A.P. (1999) Essential fatty acids in health and chronic disease. Am J Clin Nutr 70, 560S-569S.

141. Burr, G.O. and Burr, M.M. (1973) Nutrition classics from The Journal of Biological Chemistry 82:345-67, 1929. A new deficiency disease produced by the rigid exclusion of fat from the diet. Nutr. Rev. 31, 248-249.

142. (1999) Dietary supplementation with n-3 polyunsaturated fatty acids and vitamin E after myocardial infarction: results of the GISSI-Prevenzione trial. Gruppo Italiano per lo Studio della Sopravvivenza nell'Infarto miocardico. Lancet 354, 447-455.

143. Bazan, N.G., Marcheselli, V.L., and Cole-Edwards, K. (2005) Brain response to injury and neurodegeneration: endogenous neuroprotective signaling. Ann. N. Y. Acad. Sci. 1053, 137-147.

144. Harris, W.S., Mozaffarian, D., Lefevre, M., Toner, C.D., Colombo, J., Cunnane, S.C., Holden, J.M., Klurfeld, D.M., Morris, M.C., and Whelan, J. (2009) Towards establishing dietary reference intakes for eicosapentaenoic and docosahexaenoic acids. J. Nutr. 139, 804S-819S.

145. Kromann, N. and Green, A. (1980) Epidemiological studies in the Upernavik district, Greenland. Incidence of some chronic diseases 1950-1974. Acta Med. Scand. 208, 401-406.

146. Gronert, K. and Hassan, I.R. (2007) Reaping the benefits of renal protective lipid autacoids. Drug Discov. Today Dis. Mech. 4, 3-10.

147. Mori, T.A. (2006) Omega-3 fatty acids and hypertension in humans. Clin. Exp. Pharmacol. Physiol. 33, $842-846$.

148. Blok, W.L., Katan, M.B., and van der Meer, J.W. (1996) Modulation of inflammation and cytokine production by dietary (n-3) fatty acids. J. Nutr. 126, 1515-1533.

149. Simopoulos, A.P. (2002) Omega-3 fatty acids in inflammation and autoimmune diseases. J. Am. Coll. Nutr. 21, 495505 .

150. Tomobe, Y.I., Morizawa, K., Tsuchida, M., Hibino, H., Nakano, Y., and Tanaka, Y. (2000) Dietary docosahexaenoic acid suppresses inflammation and immunoresponses in contact hypersensitivity reaction in mice. Lipids 35, 61-69.

151. James, M.J., Gibson, R.A., and Cleland, L.G. (2000) Dietary polyunsaturated fatty acids and inflammatory mediator production. Am. J. Clin. Nutr. 71, 343S-348S. 
152. Hibbeln, J.R., Nieminen, L.R., Blasbalg, T.L., Riggs, J.A., and Lands, W.E. (2006) Healthy intakes of n-3 and n-6 fatty acids: estimations considering worldwide diversity. Am. J. Clin. Nutr. 83, 1483S-1493S.

153. De Caterina, R., Liao, J.K., and Libby, P. (2000) Fatty acid modulation of endothelial activation. Am. J. Clin. Nutr.71, 213S-223S

154. Bazan, N.G. (2009) Cellular and molecular events mediated by docosahexaenoic acid-derived neuroprotectin D1 signaling in photoreceptor cell survival and brain protection. Prostaglandins Leukot. Essent. Fatty Acids 81, $205-211$.

155. Simopoulos, A.P. (2009) Omega-6/omega-3 essential fatty acids: biological effects. World Rev. Nutr. Diet 99, 1-16.

156. Mukherjee, P.K., Chawla, A., Loayza, M.S., and Bazan, N.G. (2007) Docosanoids are multifunctional regulators of neural cell integrity and fate: significance in aging and disease. Prostaglandins Leukot. Essent. Fatty Acids 77, 233238.

157. Hodge, W.G., Barnes, D., Schachter, H.M., Pan, Y.I., Lowcock, E.C., Zhang, L., Sampson, M., Morrison, A., Tran, K., Miguelez, M., and Lewin, G. (2006) The evidence for efficacy of omega-3 fatty acids in preventing or slowing the progression of retinitis pigmentosa: a systematic review. Can. J. Ophthalmol. 41, 481-490.

158. Hodge, W.G., Barnes, D., Schachter, H.M., Pan, Y.I., Lowcock, E.C., Zhang, L., Sampson, M., Morrison, A., Tran, K., Miguelez, M., and Lewin, G. (2007) Evidence for the effect of omega-3 fatty acids on progression of age-related macular degeneration: a systematic review. Retina 27, 216-221.

159. Hodge, W.G., Schachter, H.M., Barnes, D., Pan, Y., Lowcock, E.C., Zhang, L., Sampson, M., Morrison, A., Tran, K., Miguelez, M., and Lewin, G. (2006) Efficacy of omega-3 fatty acids in preventing age-related macular degeneration: a systematic review. Ophthalmology 113, 1165-1172; quiz 1172-1163, 1178.

160. Tuo, J., Ross, R.J., Herzlich, A.A., Shen, D., Ding, X., Zhou, M., Coon, S.L., Hussein, N., Salem, N., Jr., and Chan, C.C. (2009) A high omega-3 fatty acid diet reduces retinal lesions in a murine model of macular degeneration. Am. J. Pathol. 175, 799-807.

161. Connor, K.M., SanGiovanni, J.P., Lofqvist, C., Aderman, C.M., Chen, J., Higuchi, A., Hong, S., Pravda, E.A., Majchrzak, S., Carper, D., Hellstrom, A., Kang, J.X., Chew, E.Y., Salem, N., Jr., Serhan, C.N., and Smith, L.E. (2007) Increased dietary intake of omega-3-polyunsaturated fatty acids reduces pathological retinal angiogenesis. Nat. Med. 13, 868-873.

162. SanGiovanni, J.P., Parra-Cabrera, S., Colditz, G.A., Berkey, C.S., and Dwyer, J.T. (2000) Meta-analysis of dietary essential fatty acids and long-chain polyunsaturated fatty acids as they relate to visual resolution acuity in healthy preterm infants. Pediatrics 105, 1292-1298.

163. SanGiovanni, J.P., Berkey, C.S., Dwyer, J.T., and Colditz, G.A. (2000) Dietary essential fatty acids, long-chain polyunsaturated fatty acids, and visual resolution acuity in healthy fullterm infants: a systematic review. Early Hum. Dev. 57, 165-188.

164. SanGiovanni, J.P., Chew, E.Y., Clemons, T.E., Davis, M.D., Ferris, F.L., 3rd, Gensler, G.R., Kurinij, N., Lindblad, A.S., Milton, R.C., Seddon, J.M., and Sperduto, R.D. (2007) The relationship of dietary lipid intake and age-related macular degeneration in a case-control study: AREDS Report No. 20. Arch. Ophthalmol. 125, 671-679.

165. SanGiovanni, J.P., Chew, E.Y., Agron, E., Clemons, T.E., Ferris, F.L., 3rd, Gensler, G., Lindblad, A.S., Milton, R.C., Seddon, J.M., Klein, R., and Sperduto, R.D. (2008) The relationship of dietary omega-3 long-chain polyunsaturated fatty acid intake with incident age-related macular degeneration: AREDS Report No. 23. Arch. Ophthalmol. 126, 1274-1279.

166. Sangiovanni, J.P., Agron, E., Meleth, A.D., Reed, G.F., Sperduto, R.D., Clemons, T.E., and Chew, E.Y. (2009) \{omega\}-3 Long-chain polyunsaturated fatty acid intake and 12-y incidence of neovascular age-related macular degeneration and central geographic atrophy: AREDS Report 30, a prospective cohort study from the Age-Related Eye Disease Study. Am. J. Clin. Nutr. 90, 1601-1607.

167. Miljanovic, B., Trivedi, K.A., Dana, M.R., Gilbard, J.P., Buring, J.E., and Schaumberg, D.A. (2005) Relation between dietary n-3 and n-6 fatty acids and clinically diagnosed dry eye syndrome in women. Am. J. Clin. Nutr. 82, 887-893.

168. Rashid, S., Jin, Y., Ecoiffier, T., Barabino, S., Schaumberg, D.A., and Dana, M.R. (2008) Topical omega-3 and omega-6 fatty acids for treatment of dry eye. Arch. Ophthalmol. 126, 219-225.

169. Hong, S., Gronert, K., Devchand, P.R., Moussignac, R.L., and Serhan, C.N. (2003) Novel docosatrienes and 17Sresolvins generated from docosahexaenoic acid in murine brain, human blood, and glial cells. Autacoids in antiinflammation. J. Biol. Chem. 278, 14677-14687.

170. Serhan, C.N., Yacoubian, S., and Yang, R. (2008) Anti-inflammatory and proresolving lipid mediators. Annu. Rev. Pathol. 3, 279-312.

171. Serhan, C.N. (2006) Resolution phases of inflammation: novel endogenous anti-inflammatory and proresolving lipid mediators and pathways. Annu. Rev. Immunol. 25, 101-137.

172. Ariel, A. and Serhan, C.N. (2007) Resolvins and protectins in the termination program of acute inflammation. Trends Immunol. 28, 176-183.

173. Marcheselli, V.L., Hong, S., Lukiw, W.J., Tian, X.H., Gronert, K., Musto, A., Hardy, M., Gimenez, J.M., Chiang, N., Serhan, C.N., and Bazan, N.G. (2003) Novel docosanoids inhibit brain ischemia-reperfusion-mediated leukocyte infiltration and pro-inflammatory gene expression. J. Biol. Chem. 278, 43807-43817.

174. Bazan, N.G. (2007) Omega-3 fatty acids, pro-inflammatory signaling and neuroprotection. Curr. Opin. Clin. Nutr. Metab. Care 10, 136-141. 
175. Bazan, N.G. (2009) Neuroprotectin D1-mediated anti-inflammatory and survival signaling in stroke, retinal degenerations, and Alzheimer's disease. J. Lipid Res. 50(Suppl), S400-405.

176. Spite, M., Norling, L.V., Summers, L., Yang, R., Cooper, D., Petasis, N.A., Flower, R.J., Perretti, M., and Serhan, C.N. (2009) Resolvin D2 is a potent regulator of leukocytes and controls microbial sepsis. Nature 461, 1287-1291.

177. Sun, Y.P., Oh, S.F., Uddin, J., Yang, R., Gotlinger, K., Campbell, E., Colgan, S.P., Petasis, N.A., and Serhan, C.N. (2007) Resolvin D1 and its aspirin-triggered 17R epimer. Stereochemical assignments, anti-inflammatory properties, and enzymatic inactivation. J. Biol. Chem. 282, 9323-9334.

178. Arita, M., Bianchini, F., Aliberti, J., Sher, A., Chiang, N., Hong, S., Yang, R., Petasis, N.A., and Serhan, C.N. (2005) Stereochemical assignment, antiinflammatory properties, and receptor for the omega-3 lipid mediator resolvin E1. $J$. Exp. Med. 201, 713-722.

179. Serhan, C.N., Gotlinger, K., Hong, S., Lu, Y., Siegelman, J., Baer, T., Yang, R., Colgan, S.P., and Petasis, N.A. (2006) Anti-inflammatory actions of neuroprotectin D1/protectin D1 and its natural stereoisomers: assignments of dihydroxy-containing docosatrienes. J. Immunol. 176, 1848-1859.

180. Arterburn, L.M., Hall, E.B., and Oken, H. (2006) Distribution, interconversion, and dose response of n-3 fatty acids in humans. Am. J. Clin. Nutr. 83, 1467S-1476S.

181. Aveldano, M.I. and Bazan, N.G. (1983) Molecular species of phosphatidylcholine, -ethanolamine, -serine, and inositol in microsomal and photoreceptor membranes of bovine retina. J. Lipid Res. 24, 620-627.

182. Choe, H.G. and Anderson, R.E. (1990) Unique molecular species composition of glycerolipids of frog rod outer segments. Exp. Eye Res. 51, 159-165.

183. Fliesler, S.J. and Anderson, R.E. (1983) Chemistry and metabolism of lipids in the vertebrate retina. Prog. Lipid Res. 22, 79-131.

184. Neuringer, M., Connor, W.E., Lin, D.S., Barstad, L., and Luck, S. (1986) Biochemical and functional effects of prenatal and postnatal omega 3 fatty acid deficiency on retina and brain in rhesus monkeys. Proc. Natl. Acad. Sci. U. S. A. 83, 4021-4025.

185. Marszalek, J.R. and Lodish, H.F. (2005) Docosahexaenoic acid, fatty acid-interacting proteins, and neuronal function: breastmilk and fish are good for you. Annu. Rev. Cell Dev. Biol. 21, 633-657.

186. SanGiovanni, J.P. and Chew, E.Y. (2005) The role of omega-3 long-chain polyunsaturated fatty acids in health and disease of the retina. Prog. Retin. Eye Res. 24, 87-138.

187. Neuringer, M., Connor, W.E., Van Petten, C., and Barstad, L. (1984) Dietary omega-3 fatty acid deficiency and visual loss in infant rhesus monkeys. J. Clin. Invest. 73, 272-276.

188. Stinson, A.M., Wiegand, R.D., and Anderson, R.E. (1991) Recycling of docosahexaenoic acid in rat retinas during n3 fatty acid deficiency. J. Lipid Res. 32, 2009-2017.

189. Ebert, S., Weigelt, K., Walczak, Y., Drobnik, W., Mauerer, R., Hume, D.A., Weber, B.H., and Langmann, T. (2009) Docosahexaenoic acid attenuates microglial activation and delays early retinal degeneration. J. Neurochem. 110, 1863-1875.

190. Zamiri, P., Sugita, S., and Streilein, J.W. (2007) Immunosuppressive properties of the pigmented epithelial cells and the subretinal space. Chem. Immunol. Allergy 92, 86-93.

191. Bazan, N.G. (2008) Neurotrophins induce neuroprotective signaling in the retinal pigment epithelial cell by activating the synthesis of the anti-inflammatory and anti-apoptotic neuroprotectin D1. Adv. Exp. Med. Biol. 613, 39-44.

192. Mukherjee, P.K., Marcheselli, V.L., de Rivero Vaccari, J.C., Gordon, W.C., Jackson, F.E., and Bazan, N.G. (2007) Photoreceptor outer segment phagocytosis attenuates oxidative stress-induced apoptosis with concomitant neuroprotectin D1 synthesis. Proc. Natl. Acad. Sci. U. S. A. 104, 13158-13163.

193. Mukherjee, P.K., Marcheselli, V.L., Serhan, C.N., and Bazan, N.G. (2004) Neuroprotectin D1: a docosahexaenoic acid-derived docosatriene protects human retinal pigment epithelial cells from oxidative stress. Proc. Natl. Acad. Sci. U. S. A. 101, 8491-8496.

194. Tian, H., Lu, Y., Sherwood, A.M., Hongqian, D., and Hong, S. (2009) Resolvins E1 and D1 in choroid-retinal endothelial cells and leukocytes: biosynthesis and mechanisms of anti-inflammatory actions. Invest. Ophthalmol. Vis. Sci. 50, 3613-3620.

195. Zhang, F., Chen, N., Pan, Z., Gjorstrup, P., and Reinach, P.S. (2008) Resolvins stimulate human corneal epithelial cell migration. Invest. Ophthalmol. Vis. Sci. 49, E-Abstract 3396.

196. Zhang, F., Yang, H., Gjorstrup, P., and Reinach, P. (2009) Cell signaling pathways underlying resolvin induced increases in human corneal epithelial cell migration: effects of RX-10001 (RvE1) and RX-10008. Invest. Ophthalmol. Vis. Sci. 50, E-Abstract 3492.

197. Li, N., He, J., Gjorstrup, P., and Bazan, H.E. (2008) The resolvin E1 analogs, RX-10065 and RX-1005 improve tear production and decrease inflammation in a mouse dry eye model. Invest. Ophthalmol. Vis. Sci. 121, E-Abstract 148.

198. Arita, M., Yoshida, M., Hong, S., Tjonahen, E., Glickman, J.N., Petasis, N.A., Blumberg, R.S., and Serhan, C.N. (2005) Resolvin E1, an endogenous lipid mediator derived from omega-3 eicosapentaenoic acid, protects against 2,4,6-trinitrobenzene sulfonic acid-induced colitis. Proc. Natl. Acad. Sci. U. S. A. 102, 7671-7676.

199. Haworth, O., Cernadas, M., Yang, R., Serhan, C.N., and Levy, B.D. (2008) Resolvin E1 regulates interleukin 23, interferon-gamma and lipoxin A4 to promote the resolution of allergic airway inflammation. Nat. Immunol. 9, 873879. 
200. He, J. and Bazan, H.E. (2010) Omega-3 fatty acids in dry eye and corneal nerve regeneration after refractive surgery. Prostaglandins Leukot. Essent. Fatty Acids 82, 319-325.

201. Cortina, M.S., He, J., Li, N., Bazan, N.G., and Bazan, H.E. (2010) Neuroprotectin D1 synthesis and corneal nerve regeneration after experimental surgery and treatment with PEDF plus DHA. Invest. Ophthalmol. Vis. Sci. 51, 804810 .

202. Esquenazi, S., Bazan, H.E., Bui, V., He, J., Kim, D.B., and Bazan, N.G. (2005) Topical combination of NGF and DHA increases rabbit corneal nerve regeneration after photorefractive keratectomy. Invest. Ophthalmol. Vis. Sci. 46, 3121-3127.

This article should be cited as follows:

Liclican, E.L. and Gornert, K. (2010) Molecular circuits of resolution in the eye. TheScientificWorldJOURNAL 10, $1029-1047$. DOI 10.1100/tsw.2010.99. 

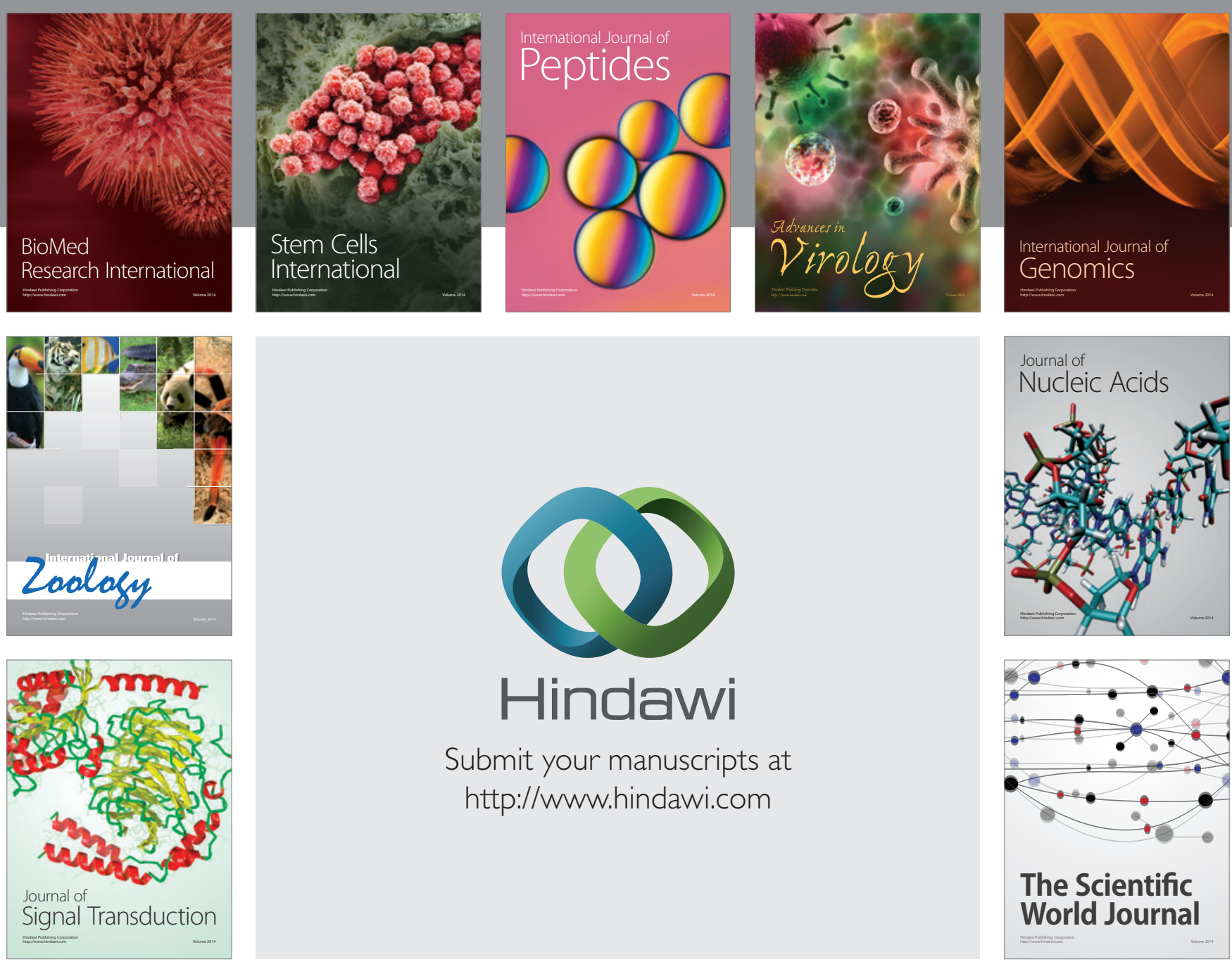

Submit your manuscripts at

http://www.hindawi.com
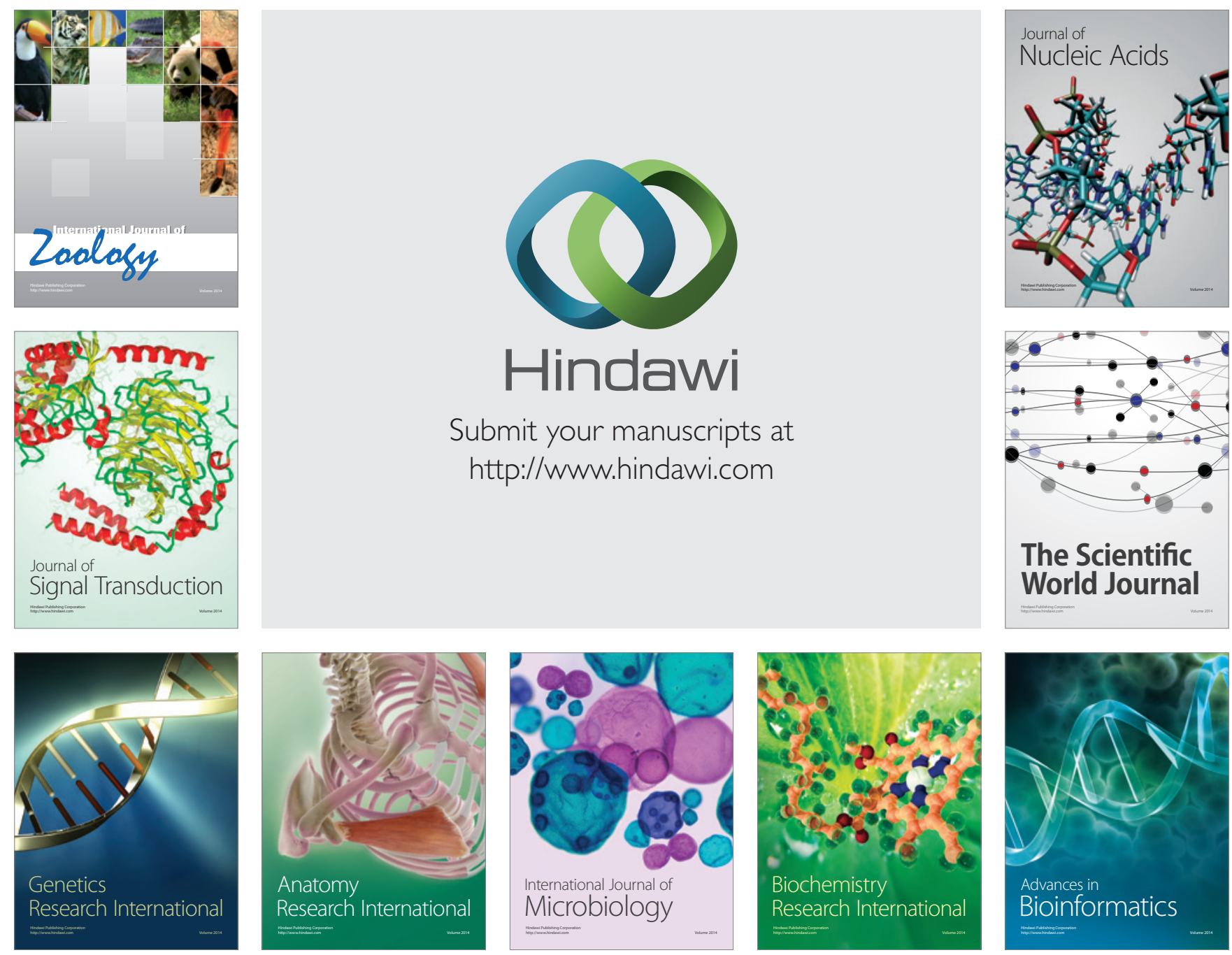

The Scientific World Journal
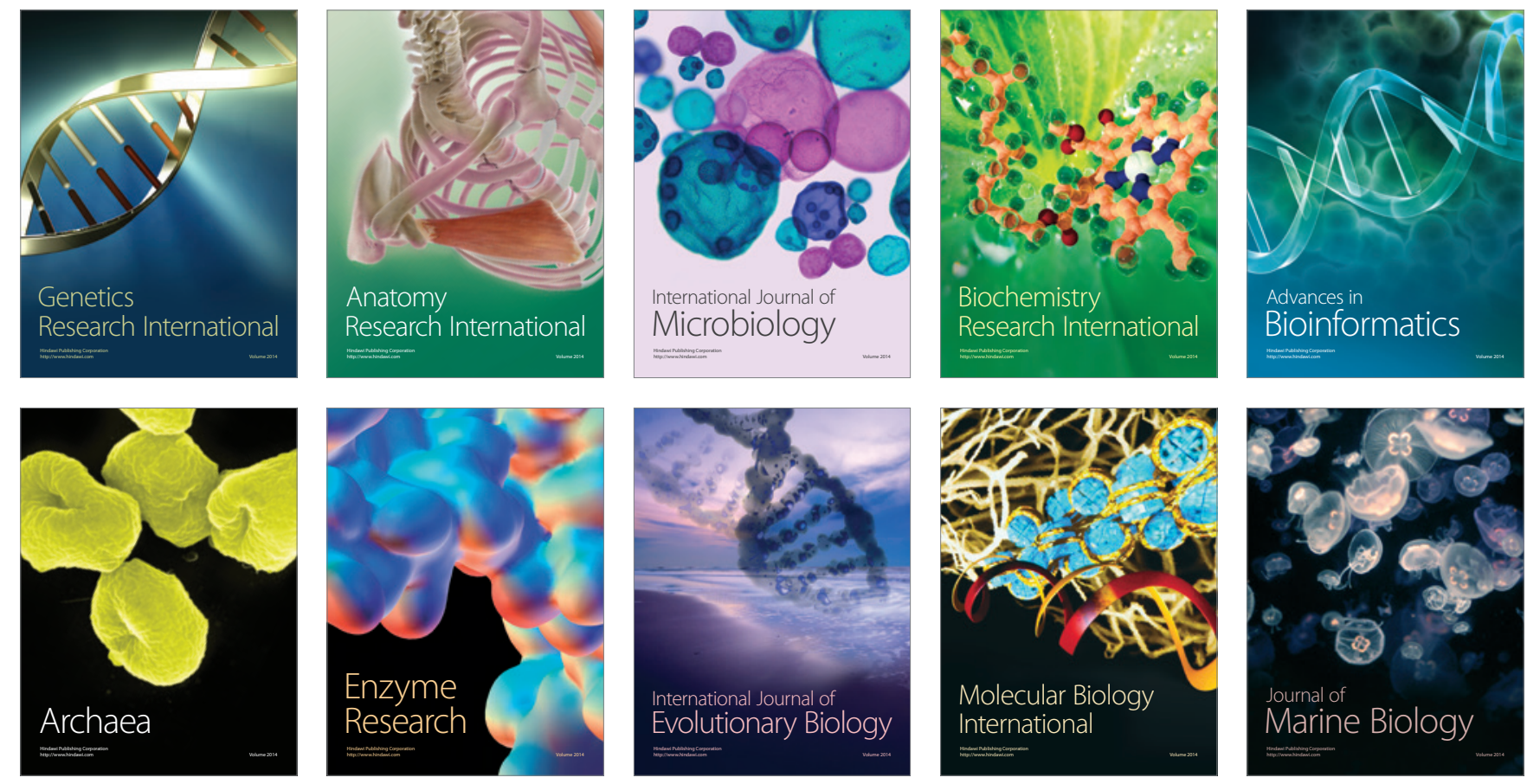